\title{
Morfología Polínica de Especies de la Selva Mediana Subperennifolia en la Cuenca del Río Candelaria,
} CAMPECHE

\author{
Yajaira de los Angeles Sánchez-Dzib ${ }^{1,2,3}$, Susana Sosa-Nájera ${ }^{2}$ y \\ María del SoCorro LozAnO-García ${ }^{2}$ \\ ${ }^{1}$ Centro de Ecología, Pesquería y Oceanografía del Golfo de México, Universidad Autónoma de Campeche. Campeche. \\ ${ }^{2}$ Instituto de Geología, Universidad Nacional Autónoma de México. México D.F. 04510 México. \\ ${ }^{3}$ Autor para la correspondencia. Correo-e: yajasd@yahoo.com.mx
}

\begin{abstract}
Resumen: Se presenta la descripción de la morfología polínica de 81 especies pertenecientes a 29 familias de la selva mediana subperennifolia en la cuenca del río Candelaria, Campeche. Se describe el polen de algunas especies endémicas de la selva mediana subperennifolia de la península de Yucatán como son: Diospyros cuneata, Croton icche, Acacia gaumeri, Bauhinia erithrocalyx, Calliandra houstoniana, Lonchocarpus longistylus, Trichilia minutiflora, Coccoloba reflexiflora, Neomillispaughia emarginata, Randia longiloba, Talisia floresii, Thinouia paucidentata and Pouteria amygdalina. Las descripciones palinológicas incluyen datos sobre la estructura y ornamentación de la exina, aberturas, tamaño y forma. El polen de cada especie se ilustra con microfotografías que muestran los detalles de la exina y aberturas.
\end{abstract}

Palabras clave: Polen, morfología polínica, selva tropical, Península de Yucatán.

\begin{abstract}
Detailed pollen morphology of 81 species belonging to the semi-evergreen tropical forest of the Candelaria River Basin, Campeche is presented. Pollen morphology of some endemic species from the Yucatan peninsula semi-evergree tropical forest are presented: Diospyros cuneata, Croton icche, Acacia gaumeri, Bauhinia erithrocalyx, Calliandra houstoniana, Lonchocarpus longistylus, Trichilia minutiflora, Coccoloba reflexiflora, Neomillispaughia emarginata, Randia longiloba, Talisia floresii, Thinouia paucidentata and Pouteria amygdalina. Exine ornamentation, structure, apertures, form and size of the pollen grains are included in the description. Details of ornamentation and apertures are illustrated.
\end{abstract}

Keywords: Pollen morphology, tropical vegetation, Yucatan Peninsula.

$\mathbf{L}^{2}$ a cuenca del río Candelaria está localizada al suroeste de Campeche, con una vegetación caracterizada originalmente por selva mediana subperennifolia, aunque ha sido sustituída recientemente por áreas de cultivos y pastizales ocasionando severos cambios en la cobertura vegetal de la selva. La tasa de deforestación en la cuenca entre 1974 a 1986 fue de $1.2 \%$ y se incrementó a $2.2 \%$ entre $1986-$ 2002, causando alteraciones en el régimen hidrológico y la biodiversidad (Benítez et al., 2005). Conocer la dinámica de cambios en la vegetación en el pasado cercano es importante para evaluar la capacidad de los ecosistemas en recobrar su equilibrio después de un disturbio. En el caso concreto de la cuenca del Río Candelaria, los datos espaciales más antiguos corresponden a las primeras imágenes de
Satélite LANDSAT de la década de los 70's. Por lo anterior no es posible reconstruir los cambios históricos en la cobertura vegetal de la cuenca mediante técnicas convencionales. En este sentido, existen otras técnicas que contribuyen al estudio y la reconstrucción de condiciones pasadas de los ecosistemas. Este es el caso del análisis palinológico, el cual permite establecer los cambios en el hábitat, la composición y el tipo de comunidades que han existido en tiempos pasados como consecuencia de alteraciones y/o perturbaciones naturales y/o humanas.

El conocimiento detallado de la morfología polínica de las especies, es la herramienta para poder realizar las reconstrucciones paleo-ambientales robustas y caracterizar el impacto que ha sufrido la cuenca del río Candelaria en los 
últimos cientos de años. Dado que la pared y la forma de los granos de polen son características de cada especie, el conocimiento sobre la morfología polínica es la clave para identificar a un nivel taxonómico preciso los microfósiles que se depositan en ambientes lacustres. (Alvarado y Palacios, 1987; Lozano y Martínez, 1990; Lozano et al 2005, 2007). Entre las investigaciones sobre la morfología polínica de la vegetación tropical de México destaca el amplio estudio palinológico de la flora de la reserva de Sian Ka' an (Palacios et al., 1991) donde se describe el polen de 467 especies. Para Veracruz se han publicado varios trabajos sobre floras polínicas, de varios tipos de vegetación, como es el de Lozano y Martínez (1990) y Lozano et al (1995) de la selva alta perennifolia de la Estación de Biología Tropical "Los Tuxtlas". Así como el conjunto de publicaciones de la Flora de Veracruz (Ludlow et al., 1983; Ayala y Ludlow, 1983; Palacios, 1984; Pedraza, 1983).

El objetivo de este estudio es describir la morfología polínica de las especies de plantas de la selva mediana subperennifolia de la cuenca del río Candelaria que sirva de base para futuras investigaciones sobre sistemática, historia de la vegetación, y melisopalinología de esta región que cuenta con una alta biodiversidad.

\section{Materiales y Métodos}

Se elaboró un listado de especies pertenecientes a la selva mediana subperennifolia de la cuenca del río Candelaria con base en literatura especializada (Arellano et al., 2003; Flores, 2001; Rico y Gómez, 1979; Gómez, 1971; Gutiérrez, 2000; Niembro, 1993; Rzedowski, 1994; Rzedowski y Calderón, 1996; Wendt, 1998; Macías y del Amo, 2002; Martínez et al., 2001). En cuanto al estudio morfológico del polen se tomaron los botones florales obtenidos de ejemplares de herbario, del Centro de Investigaciones Históricas y Sociales de la Universidad Autónoma de Campeche (UCAM) y el del Centro de Investigación Científica de Yucatán (CICY). La preparación del material palinológico, se llevó a cabo por la técnica de acetólisis de Ertdman (1969) modificada. La observación y microfotografias del material polínico se realizó con un fotomicroscopio Olympus (BH2). Las microfotografías que se presentan tienen un aumento de $1000 \mathrm{X}$, para cada fotografía $1 \mathrm{~mm}$ equivale a $1 \mu \mathrm{y}$ únicamente en los casos en que el grano de polen es muy grande se utiliza una escala menor la cual está indicada en las láminas. Las descripciones palinológicas se basaron en la terminología de Ertdman (1969), complementándose con Kremp (1965), Punt et al., (1994), Roubik y Moreno (1991). En el estudio inicial se describieron un total de 152 granos de polen que corresponden a 97 géneros y 35 familias (Sanchez-Dzib, 2007), pero en este trabajo se presentan solamente 81 especies, las cuales no se habían descrito anteriomente para la zona de la cuenca del río Candelaria. Las descripciones palinológicas están ordenadas alfabéticamente por familias de acuerdo a Cronquist (1981) y alfabéticamente según el género y especie.

Las preparaciones palinológicas fueron depositadas en la palinoteca del Instituto de Geología de la UNAM, el herbario del Centro de Investigaciones Históricas y Sociales de la Universidad Autónoma de Campeche (UCAM) y en la palinoteca del Centro de Ecología, Pesquería y Oceanógrafa del Golfo de México (EPOMEX).

\section{Resultados}

A continuación se presentan las descripciones palinológicas considerando los siguientes caracteres morfológicos del polen: a) el tipo polínico, basándose en el número y tipos de abertura; b) las aberturas, considerando la forma, estructura, tamaño y posición; c) la exina, estructura y ornamentación señalando el tipo, la forma, la distribución de los elementos con el grosor de las capas (sexina; nexina); d) la asociación, simetría y polaridad (ASP); e) la forma del grano, indicando el contorno polar y ecuatorial; f) el tamaño en micras; g) la forma de vida (FV) de la especie y finalmente información del ejemplar.

\section{ANACARDIACEAE}

Astronium graveolens Jacq.

Lám. 1:1a-1b

Abertura: Tricolporado. Colpo largo de $25 \times 2 \mu$, colpo transversal circular $(3-4 \times 5-7 \mu)$. Área polar pequeña $(0.21)$.

Exina: Subtectada, reticulada, heterobrocada. Las lúminas aumentan de tamaño hacia los polos. Exina de $2 \mu$ de espesor. Sex 1; Nex 1. ASP: Mónada; isopolar; radiosimétrica. Forma: Subprolado; CP: semiangular; CE: elíptico. Tamaño: $\mathrm{P}=32.5 \mu(27-36 \mu) \mathrm{E}=26.8 \mu(25-29 \mu)$. FV: árbol. Ejemplar: P. Alvaro M.134. Geol. a369.

\section{APOCYNACEAE}

Aspidosperma megalocarpon Müll. Arg. Lám. 1:2a-2b

Abertura: Estefanocolporado con 6 colpos. Colpo transversal de $4 \mu$ ancho. Margo de $2.4 \mu$. Exina: Tectada, psilada. Exina de $4 \mu$ de espesor. Diferenciación entre sexina y nexina de difícil observación. ASP: Mónada, isopolar; radiosimétrica. Forma: Prolado esferoidal; CP: circular; CE: elíptico-circular. Tamaño: $\mathrm{P}=45.3 \mu(41-49 \mu) \mathrm{E}=42.4$ $\mu$ (39-47 $\mu$ ). FV: árbol. Ejemplar: E. Martínez S. 28861. Geol. a371.

Rauvolfia tetraphylla L. Lám. 1:3a-3b

Abertura: Tricolporado rara vez tetracolporado. Colpo meridional corto de $19 \times 4 \mu$. Colpo transversal lolongado circular de $5 \mu$ con un margo de $4 \mu$. Área polar grande (0.56). Exina: Tectada, psilada con patrón microreticulado. Exina de $2.5 \mu$ de espesor. Sex 2; Nex 1. ASP: Mónada, isopolar; radiosimétrica. Forma: Suboblado; CP: semiangular; CE: elíptico. Tamaño: $\mathrm{P}=33.8 \mu(26-46 \mu) \mathrm{E}=38.5 \mu(29-53 \mu)$. FV: arbusto. Ejemplar: E. Martínez S. 31399. Geol. a372. 


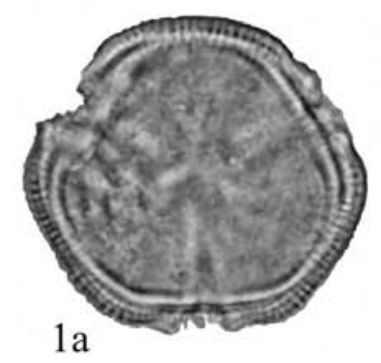

$1 \mathrm{a}$

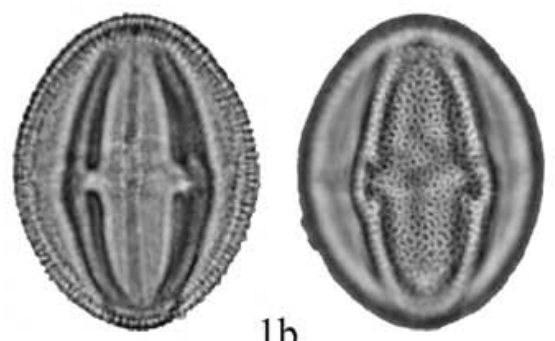

$1 b$
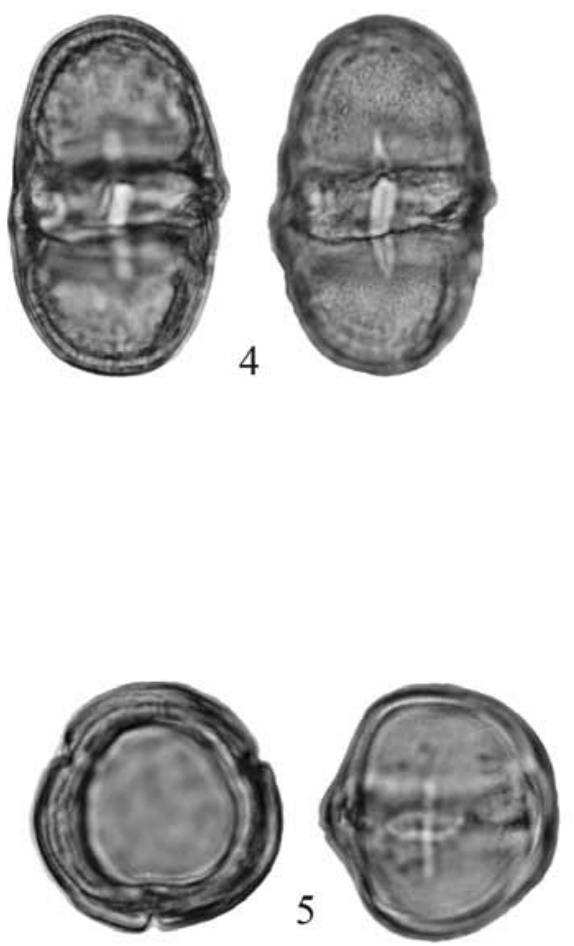

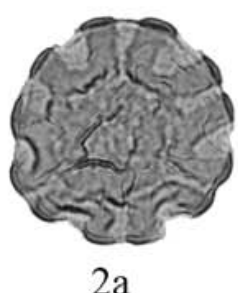

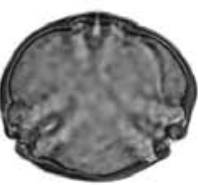

$3 a$

\section{LAMINA 1}
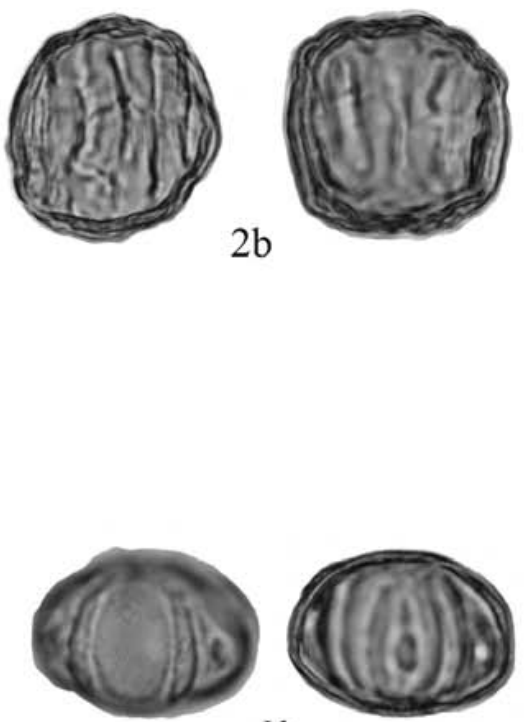

$3 b$
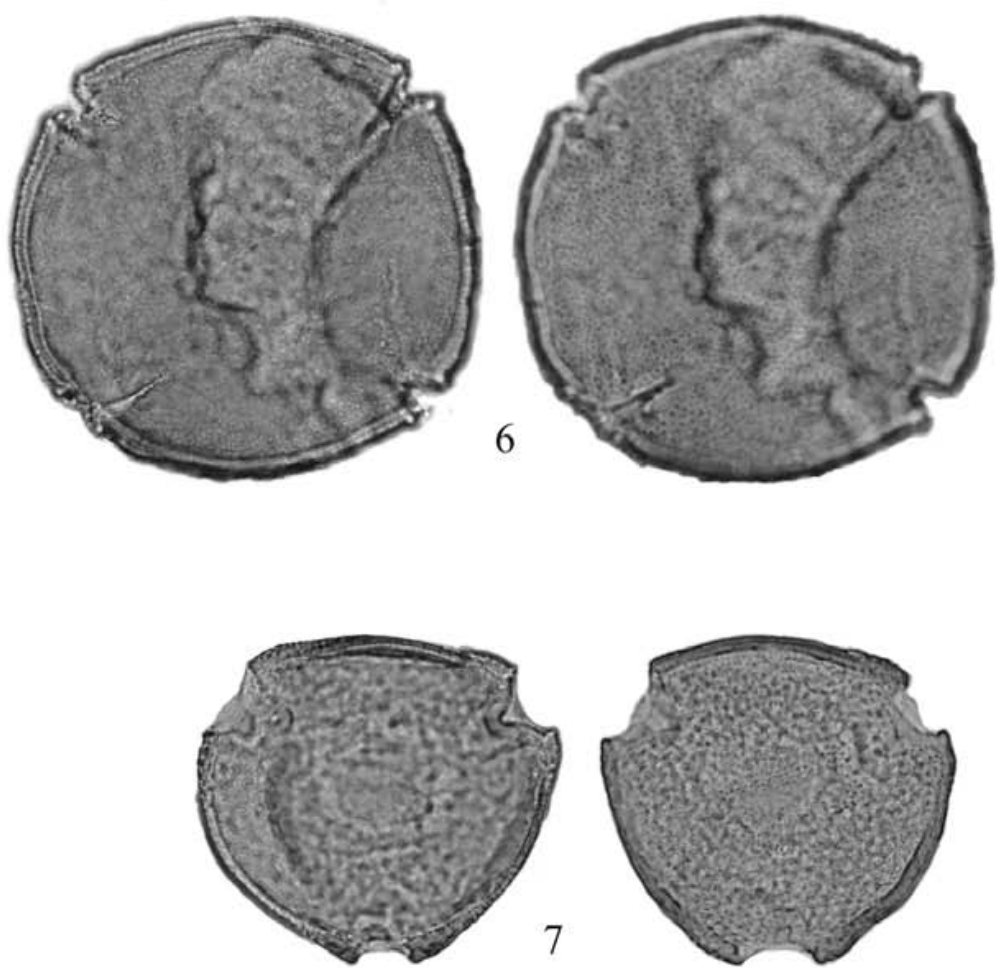

LAMINA 1. ANACARDIACEAE: Astronium graveolens (1a: vista polar; 1b: vista ecuatorial)(1000x); APOCYNACEAE: Aspidosperma megalocarpon (2a: vista polar; 2b: vista ecuatorial) (500x); Rauvolfia tetraphylla (3a: vista polar; 3b: vista ecuatorial) (500x); Stemmadenia donnell-smithii (4: vista ecuatorial) (1000x); Tabernaemontana alba (5: vista polar y ecuatorial) (1000x); Thevetia ahouai (6: vista polar y ornamentación) (500x); Thevetia peruviana (7: vista polar y ornamentación) (500x). 
Stemmadenia donnell-smithii

Lám. 1:4

(Rose) Woodson

Abertura: Trizonocolporado. Colpos pequeños de $22.1 \times$ $2.4 \mu$, colpo transversal continuo de $3 \mu$ de ancho. Exina: Tectada, psilada con patrón microreticulado. Exina de $3.3 \mu$ de espesor. Sex 2; Nex 1. ASP: Mónada; isopolar; radiosimetrica. Forma: Prolado; CE: elíptico. Tamaño: $\mathrm{P}=58.6 \mu$ (49-59 $\mu$ ) E: $36.2 \mu$ (31-42 $\mu$ ). FV: árbol o arbusto. Tipo de vegetación: selva mediana subperennifolia, selva alta perennifolia, vegetación secundaria. Ejemplar: E. Martínez S. 28067. Geol. a549.

Tabernaemontana alba Mill.

Lám. 1:5

Abertura: Tricolporado. Colpo pequeño y estrecho de $11 \times 1$ $\mu$, colpo transversal lalongado (12-16 $\mu$ ). Área polar mediana (0.39). Exina: Tectada, psilada con patrón microreticulado. Exina de $3 \mu$ de espesor. Sex 2; Nex 1. ASP: Mónada, isopolar; radiosimétrica. Forma: Prolado esferoidal; CP: semiangular; CE: elíptico. Tamaño: $\mathrm{P}=25.7 \mu(23-29 \mu) \mathrm{E}=23.9$ $\mu(20-27 \mu)$. FV: árbol o arbusto. Ejemplar: E. Cabrera y H. de Cabrera 2513. Geol. a373.

Thevetia ahouai L. A. DC.

Lám. 1:6

Abertura: Tetracolpado o pentacolpado. Área polar mediana (0.39). Exina: Tectada, perforada, patrón microreticulado. Exina de $4.6 \mu$ de espesor. Sex 3; Nex 2. ASP: Mónada, isopolar; radiosimétrica. Forma: Subprolado; CP: circular-cuadrado. Tamaño: $\mathrm{P}=120.5 \mu(94-141 \mu) \mathrm{E}=100.8 \mu$ (66-126 $\mu$ ). FV: árbol o arbusto. Ejemplar: E. Martínez S. 27257. Geol. a374.

Thevetia peruviana (Pers.) K. Schum. Lám. 1:7 Abertura: Tricolporado. Colpo meridional corto de $45 \times 7$ $\mu$, colpo transversal circular de $5 \mu$. Área polar grande (0.57). Exina: Tectada, perforada con patrón reticulado, heterobrocado. Perforaciones de $1 \mu$. Exina de $4.8 \mu$ de espesor. Sex 2; Nex 1. ASP: Mónada, isopolar; radiosimétrica. Forma: Subprolado; CP: convexa; CE: elíptico. Tamaño: $\mathrm{P}=90.5 \mu$ $(67-99 \mu) \mathrm{E}=75.5 \mu(61-106 \mu)$. FV: árbol o arbusto. Ejemplar: E. Martínez S. 27644. Geol. a376.

\section{ARECACEAE}

Sabal mauritiiformis

Lám. 2:8

(H. Karst.) Griseb. \& H. Wendl.

Abertura: Monocolpado. El colpo abarca tres cuartas partes del grano. Exina: Subtectada, reticulada, heterobrocada. Exina de $1.6 \mu$ de espesor. Sex 2; Nex 1. ASP: Mónada, isopolar; bilateral. Forma: Oblado. Tamaño: $\mathrm{E}=39.1 \mu$ $(36-43 \mu) \mathrm{e}=29.0 \mu(26-32 \mu)$. FV: palma. Ejemplar: E. Martínez S. 27536. Geol. a378

Sabal yapa C. Wright ex Becc.

Lám. 2:9

Abertura: Monocolpado. Colpo largo de polo a polo con extremos redondeados. Exina: Subtectada, microreticulada.
Exina de $2.5 \mu$ de espesor. Sex 2; Nex 1. ASP: Mónada, isopolar; bilateral. Forma: Oblado. Tamaño: $\mathrm{E}=46.6 \mu$ (43$53 \mu) \mathrm{e}=36.3 \mu(28-46 \mu)$. FV: palma. Ejemplar: Hermilo Quero R. 2387. Geol. a379.

\section{ASTERACEAE}

Milleria quinqueflora $\mathrm{L}$.

Lám. 2:10

Abertura: Tricolporado. Colpo de $16 \times 4 \mu$. Colpo transversal de $2 \mu$. Área polar grande (0.59). Exina: Tectada, equinada con patron microreticulado. Espinas agudas, espínula de $5 \mu$ de altura $\times 3.2 \mu$ de base. Exina de $6 \mu$ de espesor. Sex 5; Nex 1. ASP: Mónada; isopolar; radiosimétrica. Forma: Prolado esferoidal; CP: circular; CE: elíptico-circular. Tamaño: $\mathrm{P}=40.2 \mu(37-44 \mu) \mathrm{E}=36.7 \mu(33-42 \mu)$. FV: hierba. Ejemplar: E. Ucan y C. Chan 1599. Geol. a550

\section{BIGNONIACEAE}

Tabebuia rosea (Bertol.) A. DC.

Lám. 2:11

Abertura: Tricolpado a tricolporoidado. Colpo meridional largo de $39 \mu$. Área polar pequeña (0.14). Exina: Subtectada, reticulada, heterobrocada. Exina de $2 \mu$ de espesor. Sex 2; Nex 1. ASP: Mónada, isopolar; radiosimétrica. Forma: Subprolado; CP: circular; CE: elíptica. Tamaño: $\mathrm{P}=45.3 \mu$ $(36-52 \mu) \mathrm{E}=33.9 \mu(27-40 \mu)$. FV: árbol o arbusto. Ejemplar: P. Alvaro M.605. Geol. a225.

Tecoma stans (L.) Juss. ex Kunth

Lám.2:12

Abertura: Tricolpado. Colpo meridional largo y estrecho (40-52 $\mu$ ), membrana colpal microrreticulada. Área polar pequeña (0.16). Exina: Subtectada, reticulada, heterobrocada. Exina de $2 \mu$ de espesor. Sex 2; Nex 1. ASP: Mónada, isopolar; radiosimétrica. Forma: Subprolado; CP: circular; CE: elíptica. Tamaño: $\mathrm{P}=50.8 \mu(45-55 \mu) \mathrm{E}=40.1 \mu$ (36$44 \mu$ ). FV: árbol o arbusto. Ejemplar: Celso Gutiérrez B. 4940. Geol. a382.

\section{BOMBACACEAE}

\section{Pseudobombax ellipticum}

Lám. 2:13

(Kunth) Dugand

Abertura: Tricolporado. Colpo meridional corto de $11 \mu$, con aberturas interangulares. Área polar grande (0.66). Exina: Subtectada, reticulada, heterobrocada, las luminas disminuyen hacia los ápices convirtiendose en exina tectada. Exina de $2.1 \mu$ de espesor. Sex 2; Nex 1. ASP: Mónada, isopolar; radiosimétrica. Forma: Subprolado; CP: angular. Tamaño: $\mathrm{P}=61.2 \mu(51-66 \mu) \mathrm{E}=47 \mu(42-53 \mu)$. FV: árbol. Ejemplar: P. Zamora C. 4936. Geol. a384

\section{BORAGINACEAE}

Cordia alliodora (Ruíz \& Pav.) Oken

Lám. 2:14

Abertura: Tricolporado. Colpo meridional largo de $28 \times$ $2 \mu$. Colpo transversal lalongado de $4.2 \mu$ de ancho. Área polar mediana (0.43). Exina: Tectada, con patrón microreticulado, supramicroequinada, espinas distribuidas al azar 

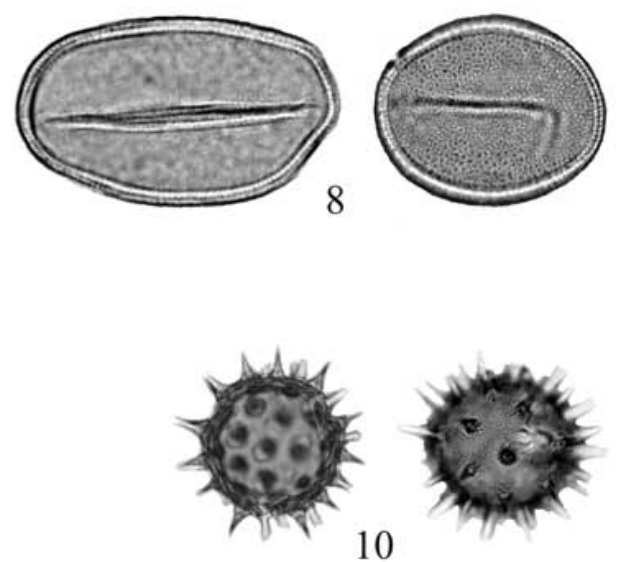

10
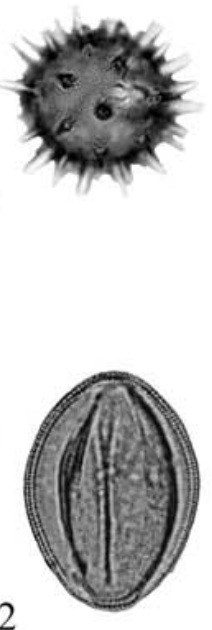

12
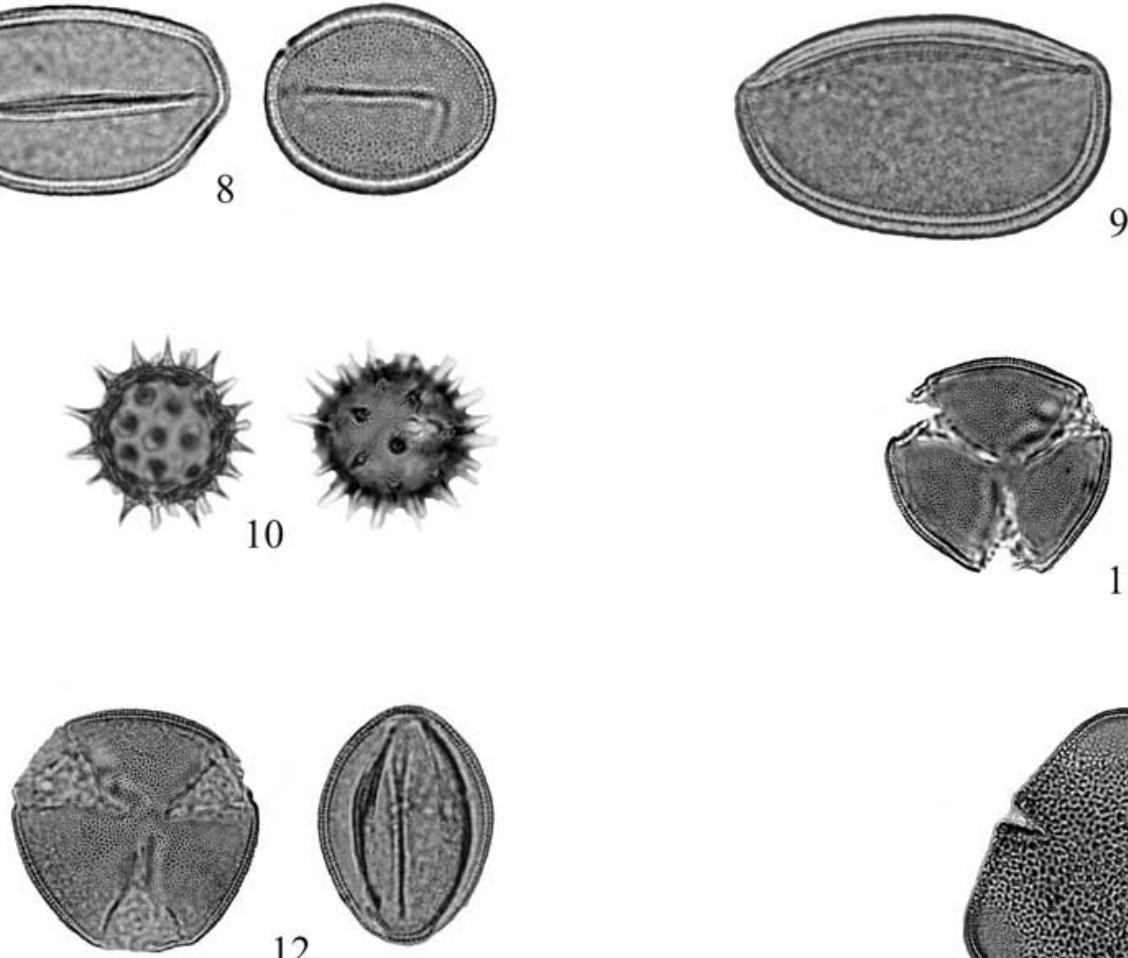

9

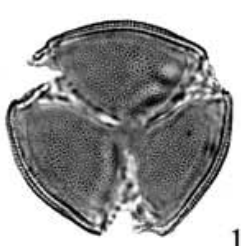

11
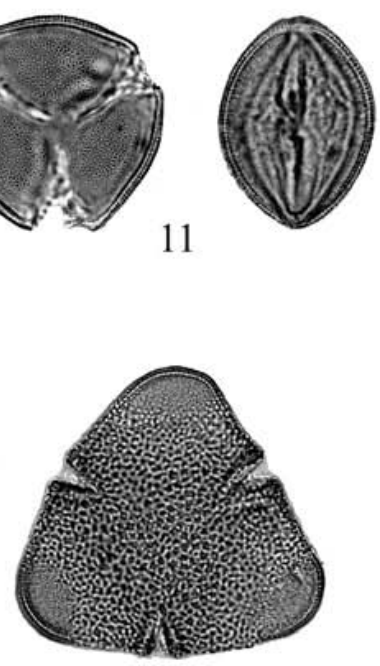

13

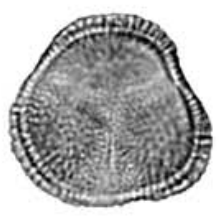

15

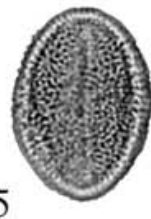

14
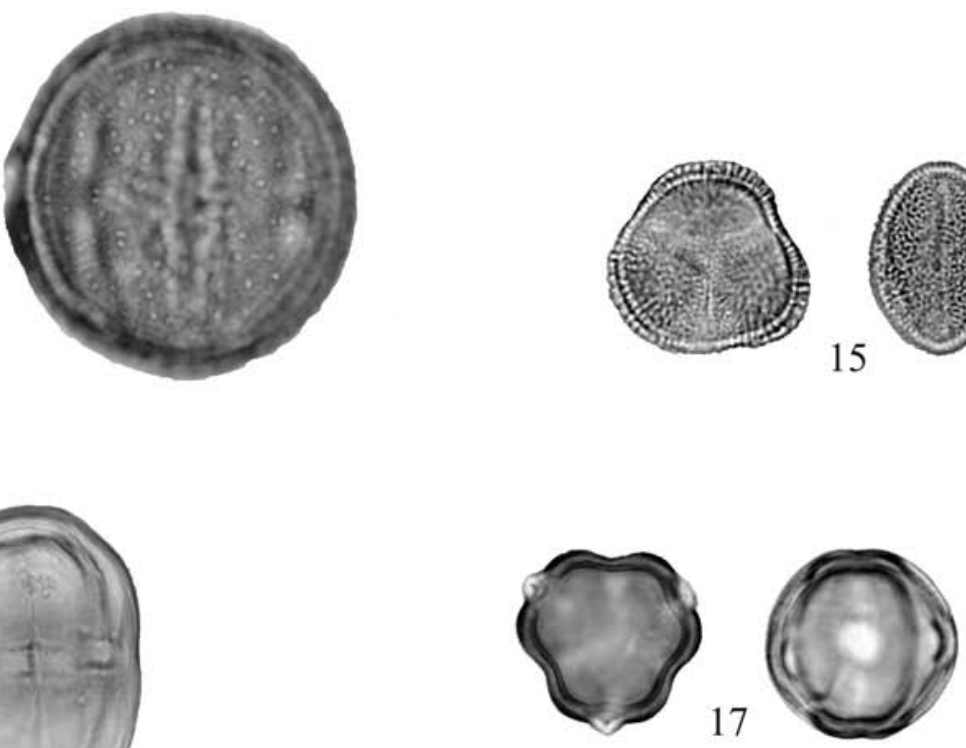

16

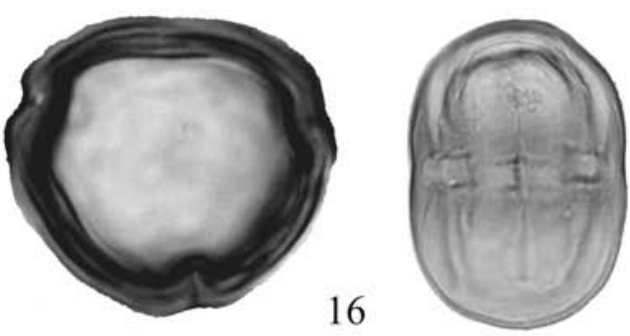

17

LAMINA 2. ARECACEAE: Sabal mauritiiformis (8: vista ecuatorial y ornamentación) (500x); Sabal yapa (9: vista ecuatorial y ornamentación) (500x); ASTERACEAE: Milleria quinqueflora (10: vista polar y ecuatorial) (1000x); BIGNONIACEAE: Tabebuia rosea (11: vista polar y ecuatorial) (500x); Tecoma stans (12: vista polar y ecuatorial) (500x); BOMBACACEAE: Pseudobombax ellipticum (13: vista polar y ornamentación) (500x); BORAGINACEAE: Cordia alliodora (14: vista polar y ecuatorial) (1000x); BRASSICACEAE: Lepidium virginicum (15: vista polar y ecuatorial) (1000x); BURSERACEAE: Protium copal (16: vista polar y ecuatorial) (1000x); COMBRETACEAE: Bucida buceras (17: vista polar y ecuatorial) (1000x). 
en el grano de polen, Exina de $2 \mu$ de espesor. Sex 2; Nex 1. ASP: Mónada, isopolar; radiosimétrica. Forma: Subprolado; CP: circular; CE: elíptico-circular. Tamaño: $\mathrm{P}=39.5$ $\mu(36-44 \mu) \mathrm{E}=34.0 \mu(31-39 \mu)$. FV: árbol. Ejemplar: Santiago Ramírez A. 132. Geol. a385.

\section{BRASSICACEAE}

Lepidium virginicum $\mathrm{L}$.

Lám. 2:15

Abertura: Tricolpado. Colpo meridional largo de $16.2 \mu$. Área polar mediana (0.32). Exina: Subtectada, microreticulada. Exina de $2 \mu$. Sex 1; Nex 1. ASP: Mónada; isopolar; radiosimétrica. Forma: Subprolado; CP: semiangular; CE: elíptico. Tamaño: $\mathrm{P}=20.6 \mu(17-30 \mu) \mathrm{E}=16.9 \mu(11-22 \mu)$. FV: hierba. Ejemplar: D. Álvarez D. 339. Geol. a553

\section{BURSERACEAE}

Protium copal

Lám. 2:16

(Schltdl. \& Cham.) Engl.

Abertura: Tricolporado. Colpo largo de $23 \times 1 \mu$. Colpo transversal lalongado rectangular $(3-4 \times 6 \mu)$. Área polar grande (0.63). Exina: Tectada, psilada. Exina de $1.3 \mu$ de espesor. Sex 1; Nex 1. ASP: Mónada, isopolar; radiosimétrica. Forma: Prolado; CP: semiangular; CE: elíptica. Tamaño: $\mathrm{P}=31.4 \mu(28-34 \mu) \mathrm{E}=21.1 \mu(19-24 \mu)$. FV: árbol. Ejemplar: P. Alvaro M. 313. Geol. a226.

\section{COMBRETACEAE}

Bucida buceras L.

Lám. 2:17

Abertura: Heterocolpado, tres colporos con membrana lisa alternando con tres pseudocolpos de $15 \mu$ de largo. Colpo transversal circular elíptico $(3 \times 4 \mu)$. Área polar grande (0.52). Exina: Tectada, psilada con patrón microreticulado. Exina de $1.9 \mu$ de espesor. Sex 2; Nex 1. ASP: Mónada, isopolar; radiosimétrica. Forma: Prolado esferoidal; CP: hexalobada; CE: elíptico-circular. Tamaño: $\mathrm{P}=19.6 \mu(19-22 \mu)$ $\mathrm{E}=18.5 \mu(17-19 \mu)$. FV: árbol. Ejemplar: Celso Gutiérrez B. 5106. Geol. a227.

\section{CONVOLVULACEAE}

Ipomoea nil (L.) Roth

Lám. 3:18

Abertura: Periporado. Poros circulares de $6 \mu$ de diámetro $(5-7 \mu)$. Exina: Tectada, equinada, espinas de $11.5 \mu$. Exina de $6.5 \mu$. Sex 4; Nex 2. ASP: Mónada; apolar; radiosimétrica. Forma: Esferoidal. Tamaño: D: $153.7 \mu$ (140-164 $\mu$ ). FV: hierba. Ejemplar: Celso Gutiérrez B. 8012. Geol. a552.

\section{EBENACEAE}

Diospyros cuneata Standl. Lám. 3:19

Abertura: Tricolporado. Colpo largo de $32 \mu$, colpo transversal lalongado rectangular (3-5 $\mu$ ), margo de $5 \mu$. Área polar pequeña (0.25). Exina: Tectada, psilada. Exina de $1.7 \mu$ de espesor. Sex 2; Nex 1. ASP: Mónada, isopolar; radiosimétrica. Forma: Subprolado; CP: circular; CE: elíptica. Tamaño: $\mathrm{P}=41.9 \mu(38-46 \mu) \mathrm{E}=32.3 \mu(28-39 \mu)$.
FV: árbol o arbusto. Ejemplar: G. Carnevali, L. Solomon, F. May Pat y L. Abdala 6321. Geol. a389.

Diospyros digyna Jacq.

Lám. 3:20

Abertura: Tricolpado a tricolporoidado. Colpo meridional largo de $24.2 \mu(19-31 \mu)$, colpo membrana microverrugada. Área polar mediana (0.30). Exina: Tectada, psilada con patrón microreticulado, Exina de $1 \mu$ de espesor. ASP: Mónada, isopolar; radiosimétrica. Forma: Subprolado; CP: circular; CE: elíptica. Tamaño: $\mathrm{P}=34.5 \mu(30-37 \mu) \mathrm{E}=$ $29.7 \mu(24-34 \mu)$. FV: árbol. Ejemplar: Santiago Ramírez A. 199. Geol. a390.

Diospyros verae-crucis (Standl.) Standl. Lám. 3:21 Abertura: Tricolpado rara vez tricolporado. Colpo meridional largo de $28 \mu$. Área polar pequeña (0.25). Exina: Subtectada, reticulada, heterobrocada. Exina de $2.9 \mu$ de espesor. Sex 3; Nex 1. ASP: Mónada, isopolar; radiosimétrica. Forma: Subprolado; CP: circular; CE: elíptica. Tamaño: $\mathrm{P}=37.4 \mu(30-45 \mu) \mathrm{E}=29.8 \mu(22-40 \mu)$. FV: árbol. Ejemplar: M. Méndez, R. Durán y P. Simá 398. Geol. a391.

\section{EUPHORBIACEAE}

Adelia barbinervis Schltdl. \& Cham.

Lám. 3:22

Abertura: Tricolporado. Colpo meridional corto de $18 \mu$, colpos membrana reticulados, colpo transversal lalongado de $3.7 \mu(3 \times 5 \mu)$. Área polar mediana (0.45). Exina: Subtectada, reticulada, heterobrocada. Exina de $2 \mu$ de espesor. Sex 1; Nex 1. ASP: Mónada, isopolar; radiosimétrica. Forma: Prolado esferoidal; CP: circular; CE: elíptica. Tamaño: $\mathrm{P}=30.1 \mu(26-38 \mu) \mathrm{E}=26.9 \mu(24-34 \mu)$. FV: árbol o arbusto. Ejemplar: E. Martínez S. 30103. Geol. a39.

\section{Croton icche Lundell}

Lám. 3:23

Abertura: Inaperturado. Exina: Intectada, clavada con patrón crotonoide. Clavas de $3.4 \mu$. ASP: Mónada, apolar; radiosimétrica. Forma: Esferoidal. Tamaño: $\mathrm{D}=41.8 \mu$ (28$50 \mu$ ). FV: hierba, arbusto o árbol. Ejemplar: E. Martínez S. 27725. Geol. a228.

Croton lundelli Standl.

Lám. 4:24

Abertura: Inaperturado. Exina: Intectada, clavada con patrón crotonoide. Clavas de $4 \mu$. Exina de $4 \mu$ de espesor. Sex 3; Nex 1. ASP: Mónada, apolar; radiosimétrica. Forma: Esferoidal. Tamaño: $\mathrm{D}=51 \mu(44-56 \mu)$. FV: hierba o arbusto. Ejemplar: P. Zamora C. 4312. Geol. a394.

Croton reflexifolius Kunth Lám. 4:25

Abertura: Inaperturado. Exina: Intectada, clavada con patrón crotonoide, clavas sostenidas por pequeñas colummelas. Clavas de $6 \mu$. Exina de $6 \mu$ de espesor. Sex 4; Nex 2. ASP: Mónada, apolar; radiosimétrica. Forma: Esferoidal. Tamaño: $\mathrm{D}=49 \mu(41-59 \mu)$. FV: arbusto. Ejemplar: Edgar Cabrera 13543. Geol. a229. 


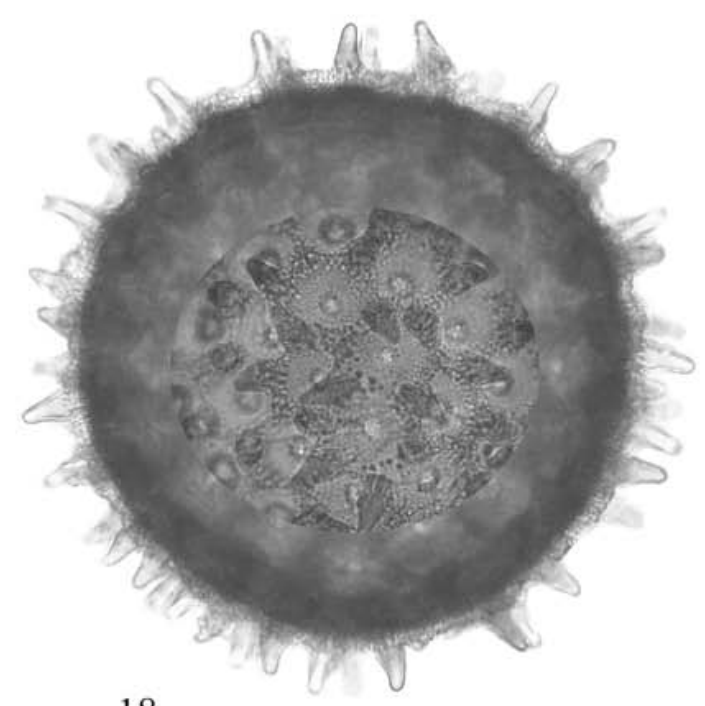

18

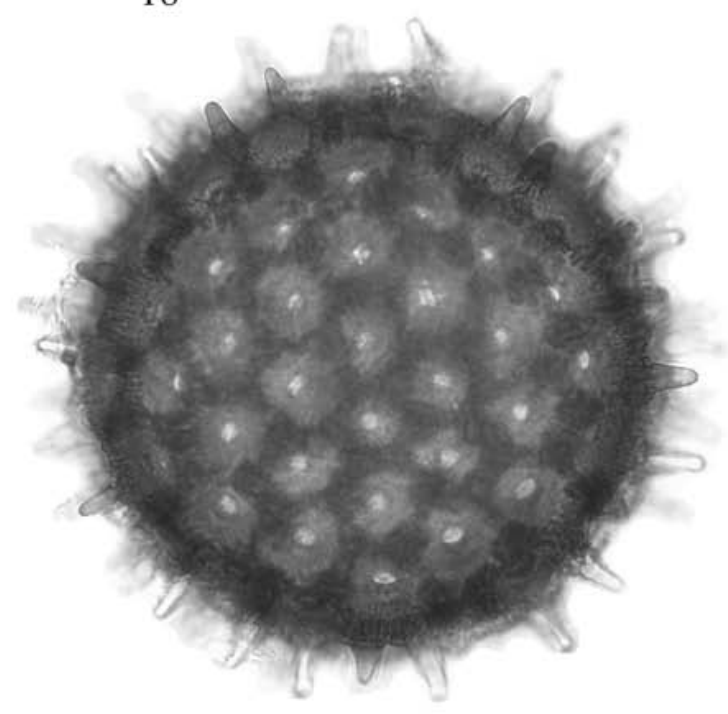

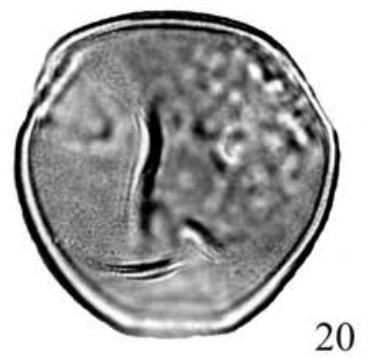

LAMINA 3
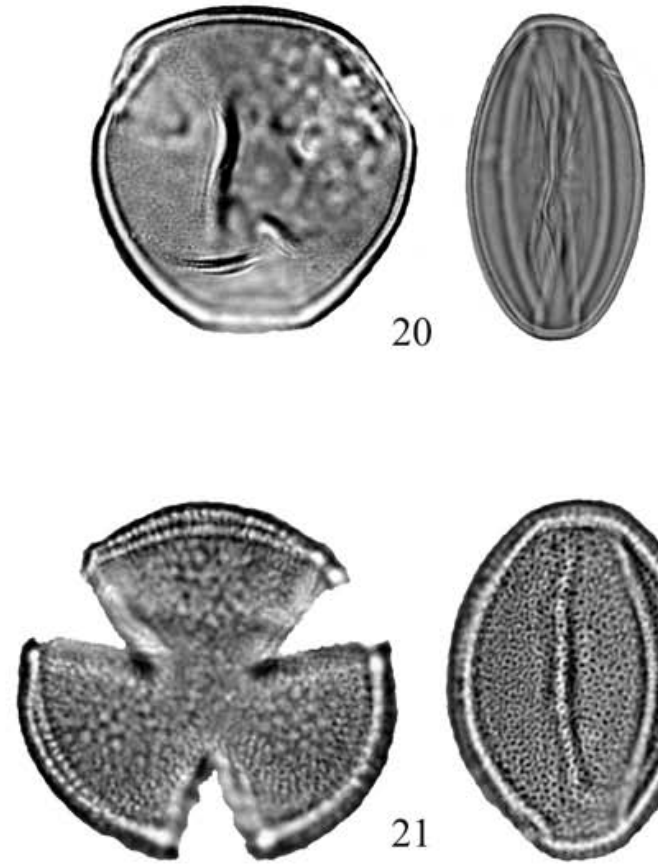

21
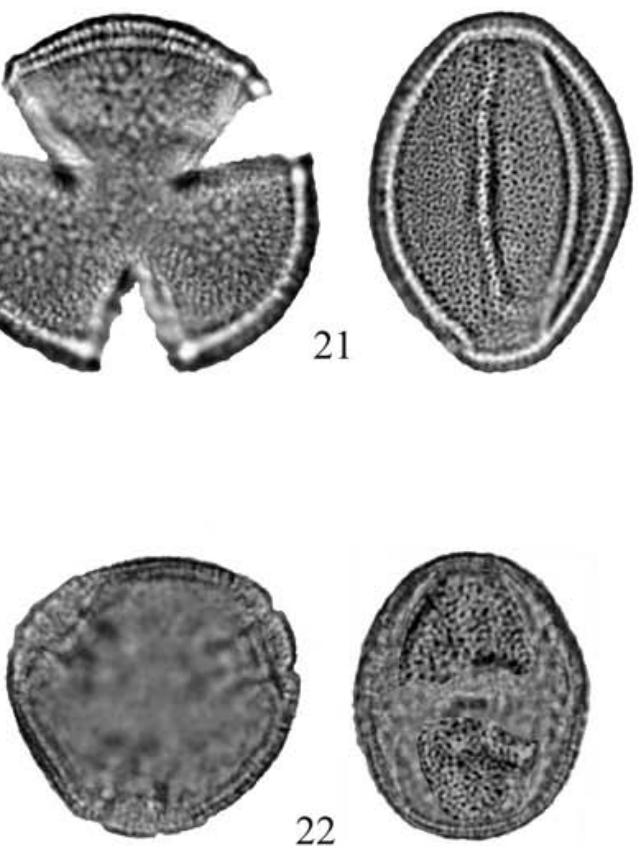

22

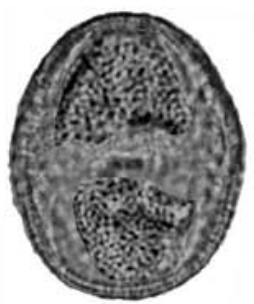

19

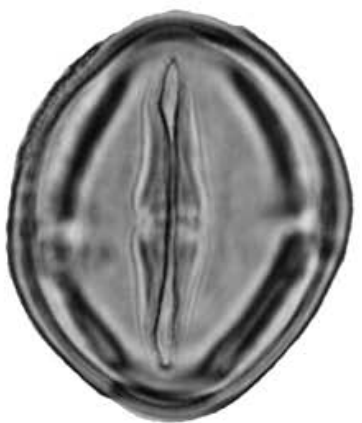

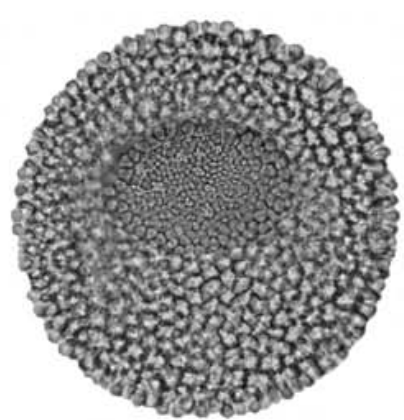

23

LAMINA 3. CONVOLVULACEAE: Ipomoea nil (18: corte óptico, poros y ornamentación) (500x); EBENACEAE: Diospyros cuneata (19: vista polar y ecuatorial) (1000x); Diospyros digyna (20: vista polar y ecuatorial) (1000x); Diospyros verae-crucis (21: vista polar y ecuatorial) (1000x); EUPHORBIACEAE: Adelia barbinervis (22: vista polar y ecuatorial) (1000x); Croton icche (23: patrón crotonoide (1000x). 


\section{FLACOURTIACEAE}

Casearia corymbosa Kunth Lám. 4:26a- 26b Abertura: Tricolporado. Colpo meridional largo de $26 \times$ $3 \mu$, colpo transversal lalongado circular elíptico $(4 \times 7 \mu)$. Área polar mediana (0.45). Exina: Tectada, psilada con patrón microreticulado. Exina de $2 \mu$ de espesor. Sex 2; Nex 1. ASP: Mónada, isopolar; radiosimétrica. Forma: Prolado esferoidal; CP: circular; CE: elíptica. Tamaño: $\mathrm{P}=35.9 \mu$ (29-40 $\mu) \mathrm{E}=32.3 \mu(27-35 \mu)$. FV: árbol o arbusto. Ejemplar: Celso Gutiérrez B. 4488. Geol. a396.

\section{Zuelania guidonia (Sw.)}

Lám. 4:27

Britton \& Millsp.

Abertura: Tetracolporado. Colpo meridional largo $21 \mu$, colpo transversal lolongado elíptico $(3.6 \times 5.6 \mu)$. Area polar mediana (0.45). Exina: Tectada, psilada con patrón microreticulado. Exina de $1.8 \mu$ de espesor. Sex 2; Nex 1. ASP: Mónada, isopolar; radiosimétrica. Forma: Subprolado; CP: circular-cuadrado; CE: elíptica. Tamaño: $\mathrm{P}=32.4 \mu$ (28-37 $\mu) \mathrm{E}=28.2 \mu(24-33 \mu)$. FV: árbol. Ejemplar: J. Calónico Soto 23024. Geol. a397.

\section{HIPPOCRATEACEAE}

Hemiangium excelsum (Kunth) A.C. Sm. Lám. 4:28 Abertura: Tricolporado. Colpo meridional largo de $25 \mu$, colpo membrana lisa, colpo transversal circular $(3.5 \mu)$. Area polar mediana (0.32). Exina: Subtectada, reticulada, heterobrocada. Exina de $1.3 \mu$ de espesor. Sex 2; Nex 1. ASP: Mónada, isopolar; radiosimétrica. Forma: Subprolado; CP: circular; CE: elíptica. Tamaño: $\mathrm{P}=29.3 \mu(23-35 \mu)$ $\mathrm{E}=22.5 \mu(19-26 \mu)$. FV: árbol. Ejemplar: Javier Chavelas 3084. Geol. a398.

\section{LAURACEAE}

Licaria campechiana (Standl.) Kosterm. Lám. 4:29 Abertura: Inaperturado. Exina: Tectada, equinada. Exina de $1 \mu$ de espesor. No se observa diferencia entre sexina y nexina. La pared se destruye facilmente con la acetólisis. ASP: Mónada, apolar; radiosimétrica. Forma: Esferoidal. Tamaño: D= $26.7 \mu(23-31 \mu)$. FV: árbol. Ejemplar: Javier Chavelas 12136. Geol. a402.

Nectandra salicifolia (Kunth) Nees

Lám. 4:30

Abertura: Inaperturado. Exina: Tectada, equinada. Exina de $1.8 \mu$ de espesor. Sex 1: Nex 1. ASP: Mónada, apolar; radiosimétrica. Forma: Esferoidal. Tamaño: $\mathrm{D}=25.5 \mu(22-33 \mu)$. FV: árbol o arbusto. Ejemplar: D. Álvarez D. 677. Geol. a400

Nectandra sanguinea Rol. ex Rottb. Lám. 4:31 Abertura: Inaperturado. Exina: Tectada, equinada. Exina de $1.2 \mu$ de espesor. No se observa diferencia entre la sexina y la nexina. ASP: Mónada, apolar; radiosimétrica. Forma: Esferoidal. Tamaño: $\mathrm{D}=25.1 \mu(20-29 \mu)$. FV: árbol. Ejemplar: F. Miranda 5348. Geol. a401.

\section{LEGUMINOSAE- CAESALPINIOIDEAE}

Bauhinia erythrocalyx Wunderlin Lám. 5:32 Abertura: Tricolporado a tetracolporado. Colpo meridional de $43 \mu$ de largo, colpo membrana microreticulado, colpo transversal de lalongado de $5 \times 3 \mu$. Área polar grande (0.61). Exina: Subtectada, reticulada, heterobrocada. Exina de $2 \mu$ de espesor. Sex 2; Nex 1. ASP: Mónada isopolar; radiosimétrica. Forma: Subprolado; CP: cuadrada a convexa. Tamaño: $\mathrm{P}=55.8 \mu(50-62 \mu) \mathrm{E}=44.5 \mu(39-52 \mu)$. FV: hierba, arbusto o árbol. Ejemplar: P. Zamora C. 4392. Geol. a412.

Caesalpinia cacalaco Bonpl. Lám. 5:33

Abertura: Tricolporado. Colpo meridional largo de $50 \mu$, colpo membrana microreticulado, colpo transversal circular de $6 \mu$. Área polar grande (0.63). Exina: Subtectada, reticulada, heterobrocada. Exina de $3.7 \mu$ de espesor. Sex 2; Nex 1. ASP: Mónada, isopolar; radiosimétrica. Forma: Subprolado; CP: convexa; CE: elíptico circular. Tamaño: $\mathrm{P}=63.6$ $\mu(60-66 \mu) \mathrm{E}=54.7 \mu(52-60 \mu)$. FV: árbol. Ejemplar: E. Cabrera y H. de Cabrera 15210. Geol. a414.

Caesalpinia vesicaria $\mathrm{L}$.

Lám. 5:34

Abertura: Tricolporado. Colpo meridional largo de $48 \mu$, colpo membrana microreticulado, colpo transversal lalongado $(3 \times 8 \mu)$, anillo de $2 \mu$. Área polar grande (0.66). Exina: Tectada, reticulada, heterobrocada. Exina de $3.6 \mu$ de espesor. Sex 2; Nex 1. ASP: Mónada, isopolar; radiosimétrica. Forma: Prolado esferoidal; CP: convexa; CE: elíptico. Tamaño: $\mathrm{P}=52.1 \mu(48-54 \mu) \mathrm{E}=49.2 \mu(42-55 \mu)$. FV: árbol o arbusto. Ejemplar: D. Álvarez D. 586. Geol. a416.

Cassia grandis L.f.

Lám. 5:35

Abertura: Tricolporado. Colpo meridional largo de $33 \mu$, colpo membrana liso, colpo transversal lalongado de $3 \mu$. Área polar mediana (0.43). Exina: Tectada, patron microreticulado. Exina de $1.8 \mu$ de espesor. Sex 2; Nex 1. ASP: Mónada, isopolar; radiosimétrica. Forma: Subprolado; CP: circular; CE: elíptico. Tamaño: $\mathrm{P}=36 \mu(33-42 \mu) \mathrm{E}=28.3$ $\mu(26-32 \mu)$. FV: árbol. Ejemplar: J. S. Flores 10467. Geol. a420.

Haematoxylum brasiletto $\mathrm{H}$. Karst. $\quad$ Lám. 5:36a-36b Abertura: Tricolporado. Colpo meridional largo de $43 \mu$, colpo membrana microreticulada, colpo transversal lalongado de $5 \times 14 \mu$. Margo de $8 \mu$. Área polar grande (0.69). Exina: Subtectada, microreticulada. Exina de $2.5 \mu$ de espesor. Sex 2; Nex 1. ASP: Mónada, isopolar; radiosimétrica. Forma: Subprolado; CP: convexa; CE: elíptico. Tamaño: $\mathrm{P}=51.5 \mu(48-57 \mu) \mathrm{E}=43.5 \mu(40-47 \mu)$. FV: árbol o arbusto. Ejemplar: E. Cabrera 15299. Geol. a426. 


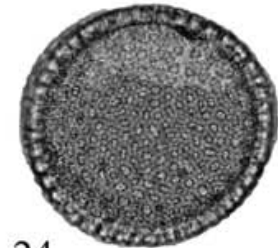

24

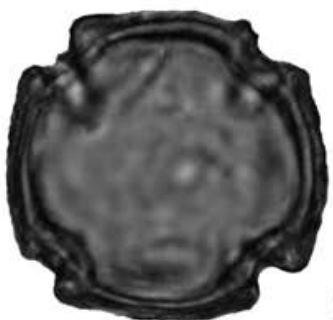

27

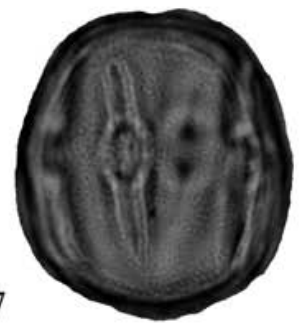

28
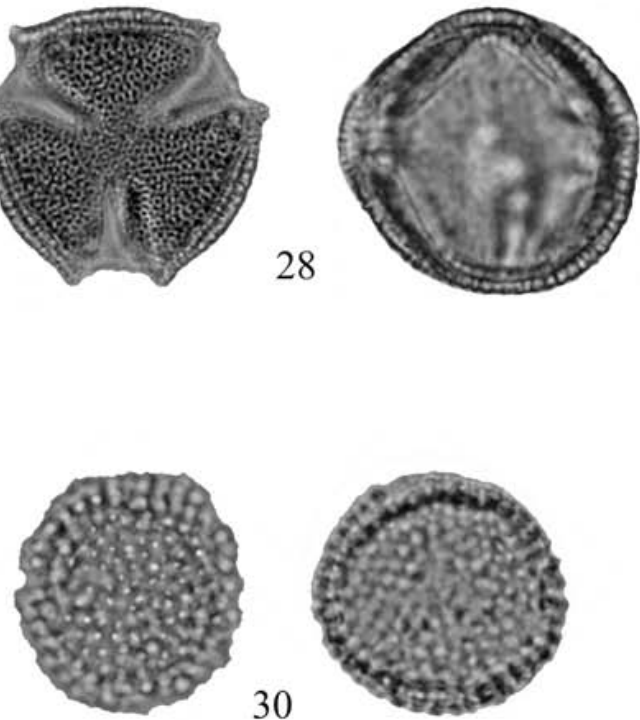

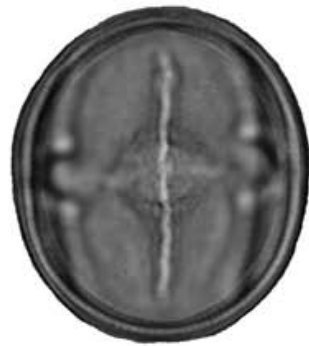

$26 b$

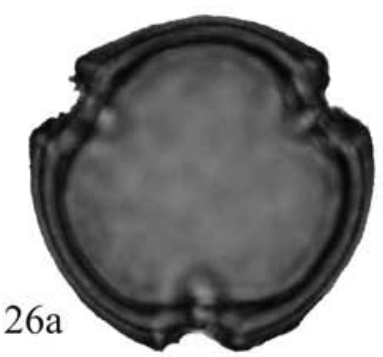

LAMINA 4
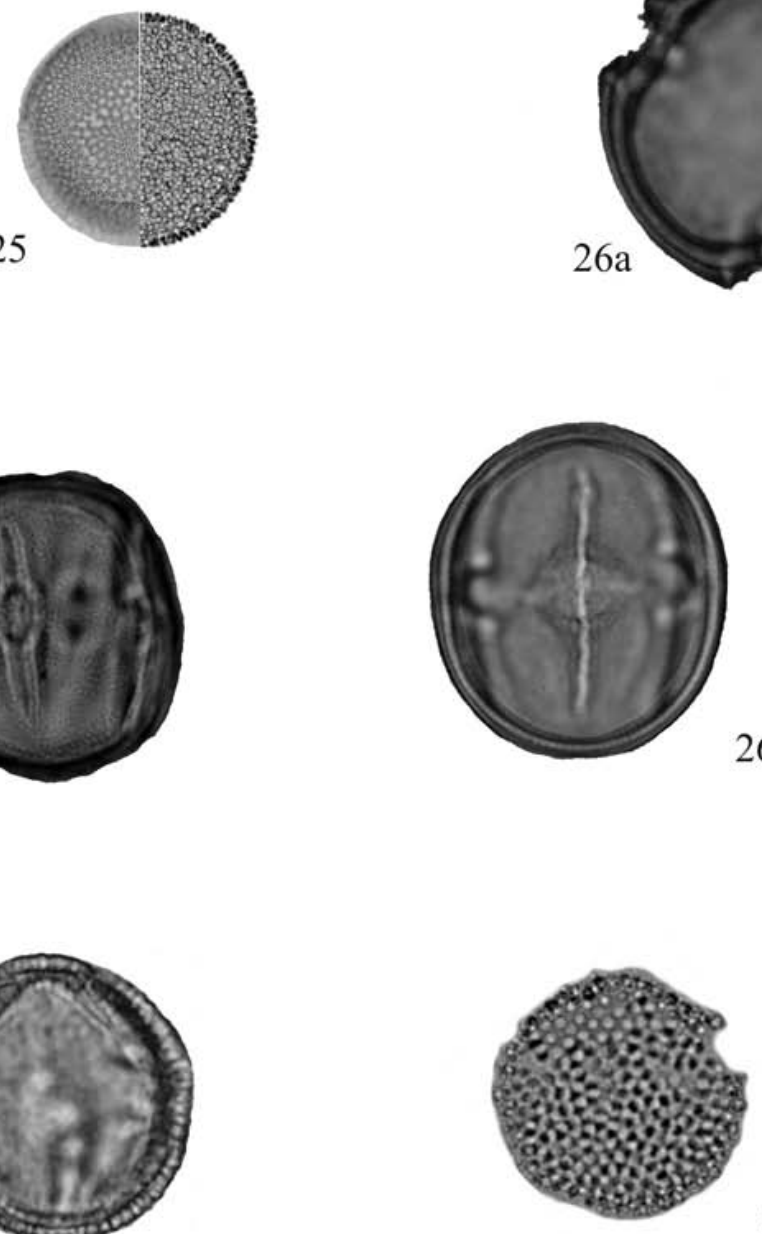

29
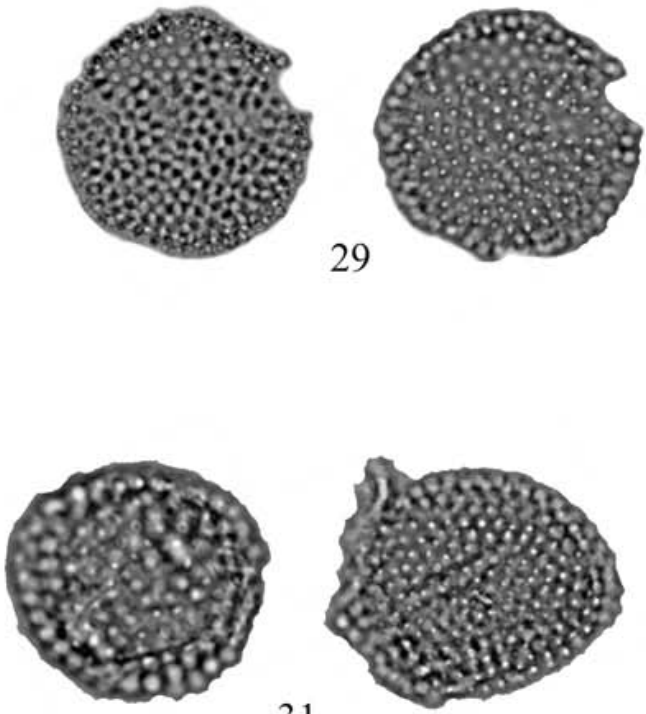

31

LAMINA 4. EUPHORBIACEAE: Croton lundelli (24: patrón crotonoide) (500x); Croton reflexifolius (25: patrón crotonoide) (500x); FLACOURTIACEAE: Casearia corimbosa (26a: vista polar; 26b: vista ecuatorial) (1000x); Zuelania guidonia (27: vista polar y ecuatorial) (1000x); HIPPOCRATEACEAE: Hemiangiun excelsum (28: vista polar y ecuatorial) (1000x); LAURACEAE: Licaria campechiana (29: ornamentación) (1000x); Nectandra salicifolia (30: ornamentación) (1000x); Nectandra sanguinea (31: ornamentación) (1000x). 


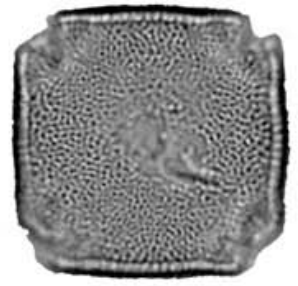

32

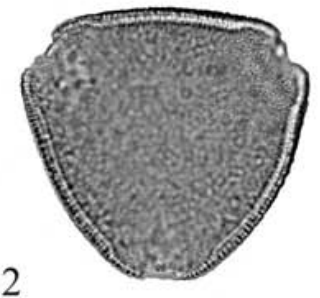

34
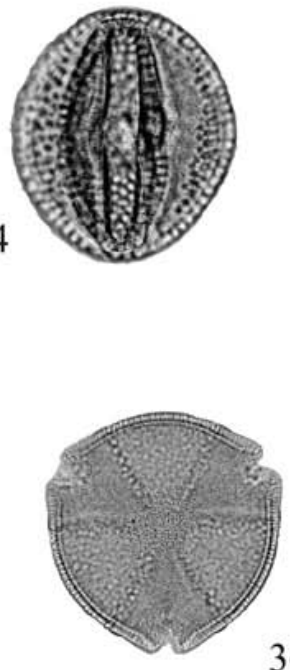

$36 \mathrm{a}$
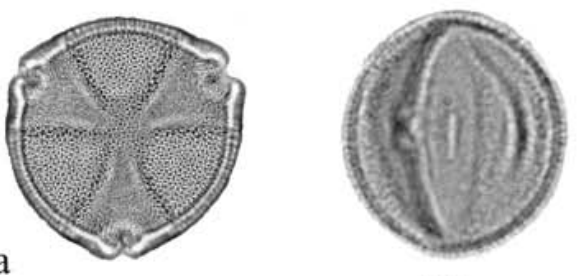

$36 \mathrm{~b}$
LAMINA 5
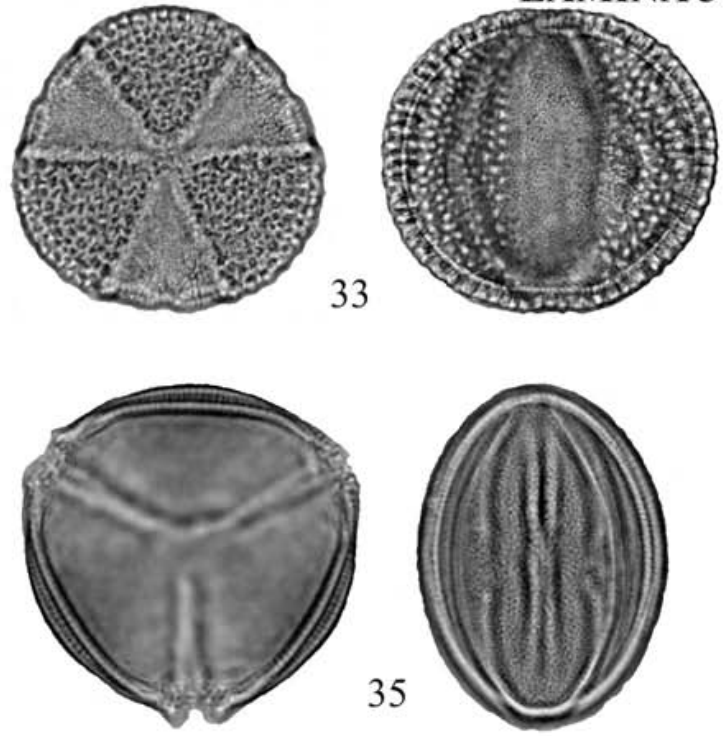
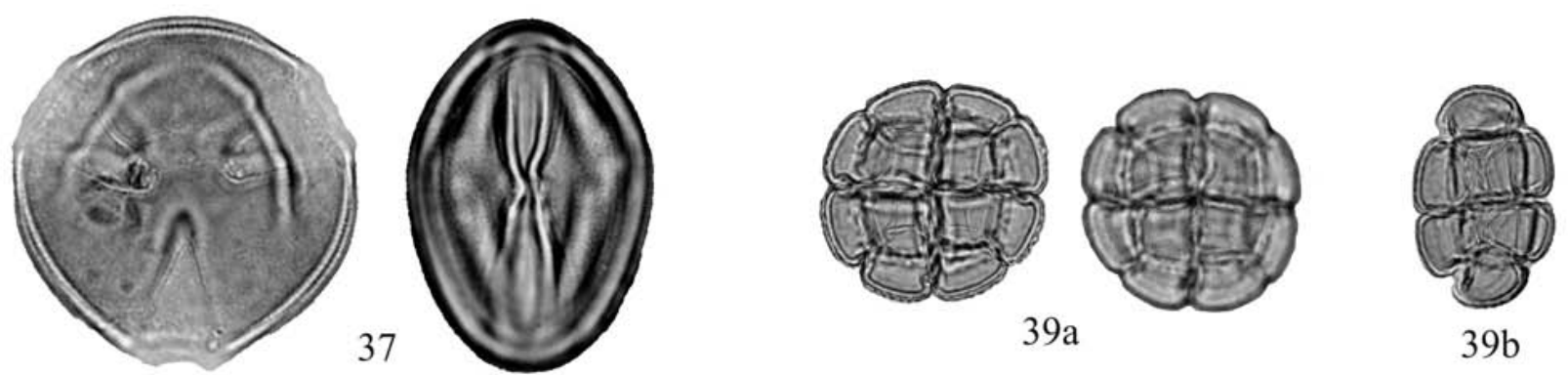

$39 a$

$39 \mathrm{~b}$
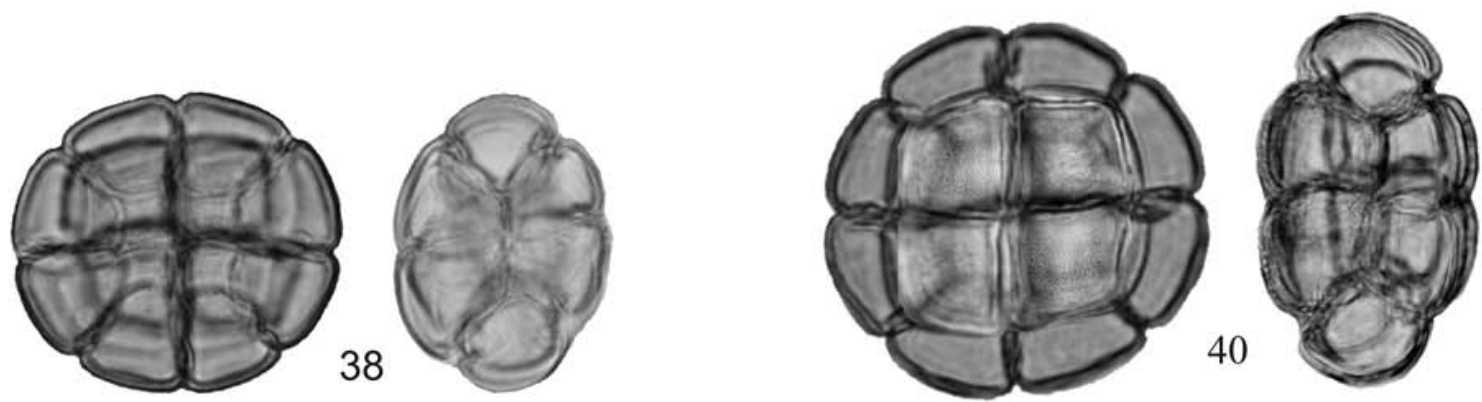

LAMINA 5. LEGUMINOSAE. CAESALPINIOIDEAE: Bauhinia erithrocalyx (32: vista polar y ornamentación) (500x); Caesalpinia cacalaco (33: vista polar y ecuatorial) (500x); Caesalpinia vesicaria (34: vista polar y ecuatorial) (500x); Cassia grandis (35: vista polar y ecuatorial) (1000x); Haematoxylum brasiletto (36a: vista polar y ornamentación; 36b: vista ecuatorial) (500x); Senna atomaria (37: vista polar y ecuatorial) (1000x); MIMOSOIDEAE: Acacia gaumeri (38: vista polar y ecuatorial) (1000x); Acacia riparia (39a: vista polar; 39b: vista ecuatorial) (500x); Albizia tomentosa (40: vista polar y ecuatorial) (500x). 


\section{Senna atomaria (L.)}

H. S. Irwin \& Barneby

Lám. 5:37

Abertura: Tricolporado. Colpo meridional largo de $30 \times 3$ $\mu$, colpo membrana lisa, colpo transversal con una constricción central de 3-5 $\mu$. Área polar mediana (0.26). Exina: Tectada, psilada con patrón microreticulado. Exina de $2 \mu$ de espesor. Sex 1; Nex 1. ASP: Mónada, isopolar; radiosimétrica. Forma: Prolado; CP: circular; CE: elíptico. Tamaño: P= $37.6 \mu(35-45 \mu) \mathrm{E}=23.3 \mu(19-31 \mu)$. FV: árbol. Ejemplar: P. Zamora C. y J. A. Hernández T. 4393. Geol. a445.

\section{LEGUMINOSAE- MIMOSOIDEAE}

\section{Acacia gaumeri S. F. Blake \\ Lám. 5:38}

Abertura: Porada. Poros de difícil observación. Exina: Tectada, psilada. Exina de $1 \mu$ de espesor. ASP: Poliada (16 mónadas); mónadas bilaterales, isopolares. Forma: Poliada circular-elíptica; mónadas piramidales. Tamaño: $\mathrm{D}=31.6 \mu$ (30-34 $\mu$ ) d: $23 \mu$. FV: árbol o arbusto. Ejemplar: P. Zamora C. y D. Méndez D. 5160. Geol. a232.

\section{Acacia riparia Kunth}

Lám. 5:39a-39b

Abertura: Porada. Poros localizados en los vértices de las monadas, poros de difícil observación. Exina: Tectada, psilada con patrón microreticulado. Exina de $2 \mu$ de espesor. Sex 1; Nex 1. ASP: Poliada (16 mónadas); mónadas bilaterales, heteropolares. Forma: Poliada circular-elíptica; mónadas piramidales. Tamaño: $\mathrm{D}=43 \mu(40-47 \mu) \mathrm{d}=30.4$ $\mu(27-34 \mu)$. FV: arbusto. Ejemplar: Celso Gutiérrez B. 4732. Geol. a408.

Albizia tomentosa (Micheli) Standl.

Lám. 5:40

Abertura: Inaperturada. Exina: Tectada, psilada con patrón microreticulado. Exina de $2 \mu$ de espesor. Sex 1; Nex 1 . ASP: Poliada (16 mónadas); mónadas bilaterales, heteropolares. Forma: Poliada circular-elíptica; mónadas piramidales. Tamaño: $\mathrm{D}=78.6 \mu(72-86 \mu) \mathrm{d}=77.3 \mu(69-86 \mu)$. FV: árbol. Ejemplar: D. Álvarez D. 635. Geol. a205.

Calliandra houstoniana (Mill.) Standl. Lám. 6:41 Abertura: Porada de 4 poros. Poros localizados en los vértices de las monadas, poros de $6 \mu$. Exina: Tectada, patron microreticulado. Exina de $2 \mu$ de espesor. Sex 2; Nex 1. ASP: Poliada (10 mónadas); mónadas bilaterales, heteropolares. Forma: Poliada; mónadas cuadrangulares a piramidales. Tamaño: $\mathrm{D}=166.7 \mu(155-182 \mu)$. FV: arbusto. Ejemplar: E. Martínez S. 29367. Geol. a418.

Calliandra tergemina (L.) Benth.

Lám. 6:42

Abertura: Porada. Poros de $7 \mu$. Exina: Tectada, patron microreticulado. Exina de $2 \mu$ de espesor. Sex 1; Nex 1. ASP: Poliada (10 mónadas); mónadas bilaterales, heteropolares. Forma: Poliada; mónadas cuadrangulares a piramidales. Tamaño: D= $154.5 \mu(137-184 \mu)$. FV: arbusto. Ejemplar: E. Martínez S. 30477. Geol. a419.
Inga vera Willd.

Lám. 6:43

Abertura: Mónadas poradas. Poros de 6-8 $\mu$. Exina: Tectada, psilada con patrón microreticulado. Exina de $1.8 \mu$ de espesor. ASP: Poliada (16 mónadas); mónadas bilaterales, heteropolares. Forma: Poliada circular-elíptica; mónadas piramidales. Tamaño: $\mathrm{D}=150.7 \mu(125-185 \mu) \mathrm{d}=98 \mu(80-116 \mu)$. FV: árbol. Ejemplar: P. Zamora C. 5188. Geol. a207.

Lysiloma acapulcense (Kunth) Benth. Lám. 6:44

Abertura: Inaperturado. Exina: Tectada, psilada con patrón microreticulado. Exina de $2 \mu$ de espesor. Sex 1; Nex 1. ASP: Poliada (16 mónadas); mónadas bilaterales, heteropolares. Forma: Poliada circular-elíptica; mónadas piramidales. Tamaño: $\mathrm{D}=82.5 \mu(71-99 \mu) \mathrm{d}=60.2 \mu(50-72 \mu)$. FV: árbol. Ejemplar: J. I. Calzada 7638. Geol. a437.

Pithecellobium dulce (Roxb.) Benth.

Lám. 7:45

Abertura: Porada. Poros localizados en los vértices, poros de 2-3 $\mu$. Exina: Tectada, psilada con patrón microreticulado. Exina de $1.5 \mu$ de espesor. Sex 2; Nex 1. ASP: Poliada (16 mónadas); mónadas bilaterales, heteropolares. Forma: Poliada circular-elíptica; mónadas piramidales. Tamaño: $\mathrm{D}=79.9 \mu(67-92 \mu) \mathrm{d}=56.3 \mu(45-69 \mu)$. FV: árbol o arbusto. Ejemplar: Celso Gutiérrez B. 5134. Geol. a440.

Pithecellobium lanceolatum

Lám. 7:46

(Humb. \& Bonpl. ex Willd) Benth.

Abertura: Porada. Poros localizados en los vértices, poros de $2 \mu$. Exina: Tectada, psilada con patrón microreticulado. Exina de $3 \mu$ de espesor. Sex 2; Nex 1. ASP: Poliada (16 mónadas); mónadas bilaterales, heteropolares. Forma: Poliada circular-elíptica; mónadas piramidales. Tamaño: $\mathrm{D}=$ $96.5 \mu(86-112 \mu) \mathrm{E}=60 \mu(52-68 \mu)$. FV: árbol o arbusto. Ejemplar: Celso Gutiérrez B. 5917. Geol. a442.

Pithecellobium saman (Jacq.) Benth.

Lám. 7:47

Abertura: Inaperturada. Exina: Tectada, psilada con patrón microreticulado. Exina de $2 \mu$ de espesor. Sex 2; Nex 1. ASP: Poliada (16 mónadas); mónadas bilaterales, heteropolares. Forma: Poliada circular-elíptica; mónadas piramidales. Tamaño: $\mathrm{D}=87.6 \mu(73-110 \mu) \mathrm{d}=56.6 \mu(52-65 \mu)$. FV: árbol. Ejemplar: Celso Gutiérrez B. 5133. Geol. a443.

\section{Pithecellobium stevensonii}

Lám. 7:48

(Standl.) Standl. \& Steyerm.

Abertura: Porada. Poros localizados en los vértices, poros de 5-8 $\mu$. Anillo de $1 \mu$. Exina: Tectada, psilada con patrón microreticulado. Exina de $2 \mu$ de espesor. Sex 2; Nex 1. ASP: Poliada (32 mónadas); mónadas bilaterales, heteropolares. Forma: Poliada circular-elíptica; mónadas piramidales. Tamaño: $\mathrm{D}=127.6 \mu(117-142 \mu) \mathrm{d}=61 \mu(53-71 \mu)$. FV: árbol o arbusto. Ejemplar: A. Sanders 9802. Geol. a444. 


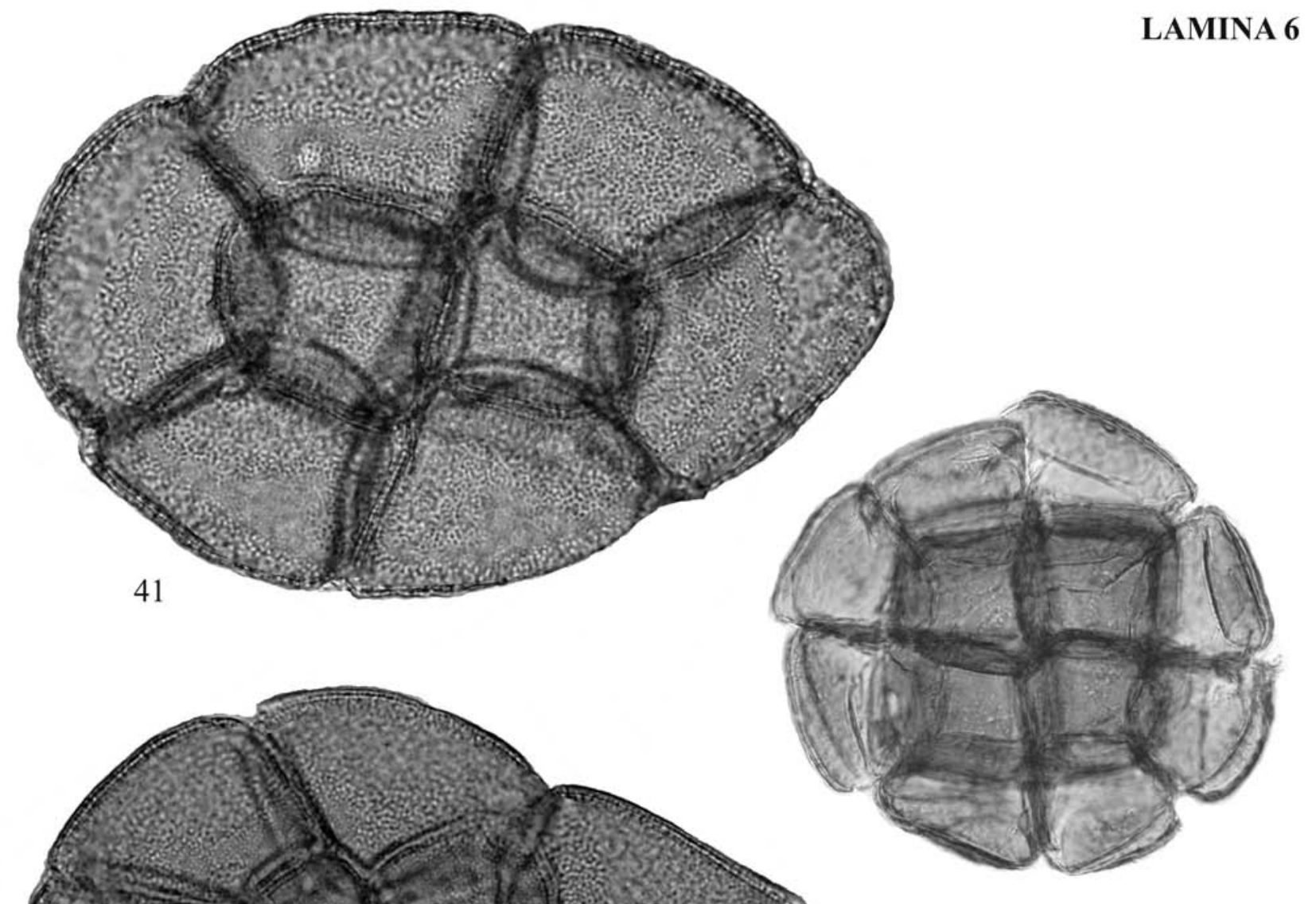

LAMINA 6
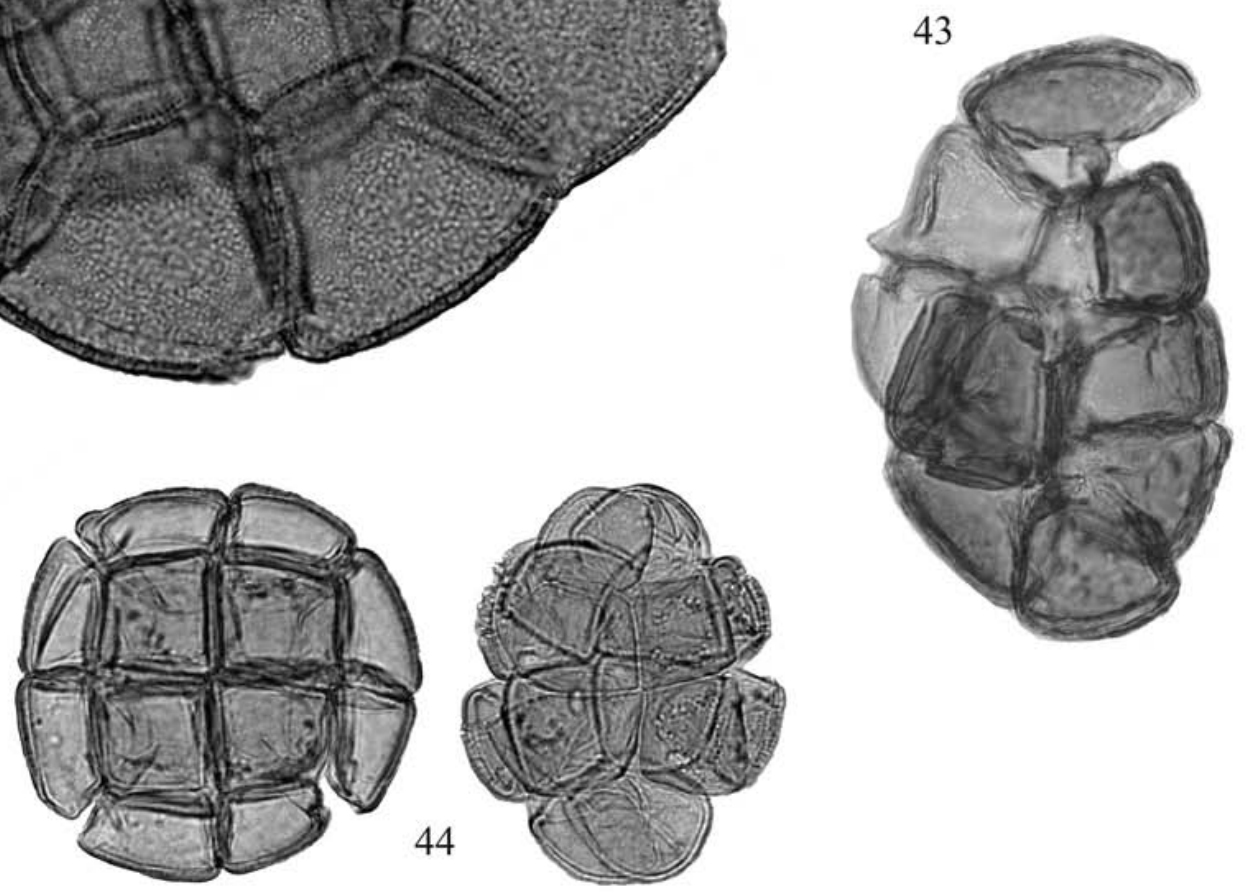

LAMINA 6. LEGUMINOSAE. MIMOSOIDEAE: Calliandra houstoniana (41: vista polar y ornamentación) (500x); Calliandra tergemina (42: vista polar y ornamentación) (500x); Inga vera (43: vista polar y ecuatorial) (500x); Lysiloma acapulcensis (44: vista polar y ecuatorial) (500x). 


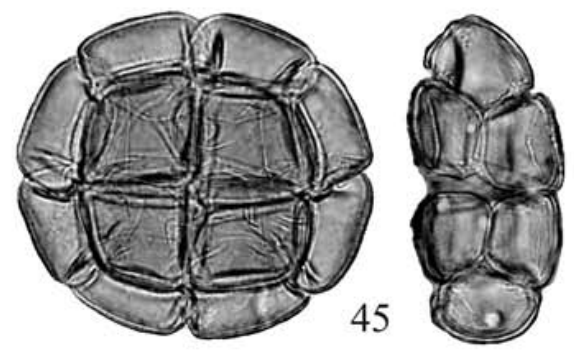

\section{LAMINA 7}
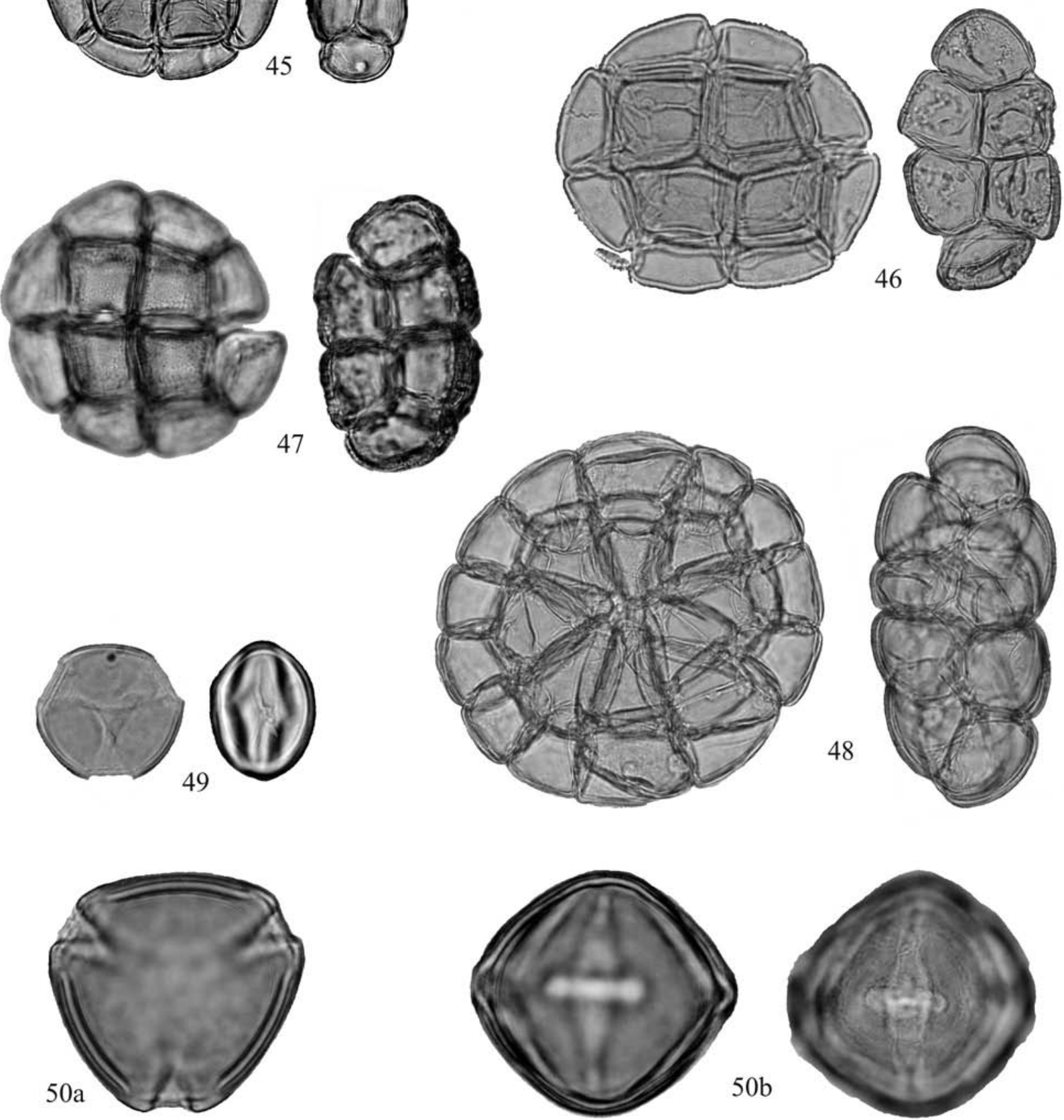

LAMINA 7. LEGUMINOSAE. MIMOSOIDEAE: Pithecellobium dulce (45: vista polar y ecuatorial) (500x); Pithecellobium lanceolatum (46: vista polar y ecuatorial) (500x); Pithecellobium saman (47: vista polar y ecuatorial) (500x); Pithecellobium stevensonii (48: vista polar y ecuatorial) (500x); PAPILIONOIDEAE: Apoplanesia paniculata (49: vista polar y ecuatorial) (1000x); Desmodium glabrum (50a: vista polar; 50b: vista ecuatorial) (1000x). 
LEGUMINOSAE- PAPILIONOIDEAE

Apoplanesia paniculata C. Presl.

Lám. 7:49

Abertura: Tricolporado. Colpo meridional largo de $19 \mu$, colpo membrana lisa, colpo transversal con constricción central. Área polar mediana (0.29). Exina: Tectada, psilada con patrón microreticulado. Exina de $1 \mu$ de espesor. ASP: Mónada, isopolar; radiosimétrica. Forma: Subprolado; CP: circular; CE: elíptica. Tamaño: $\mathrm{P}=21.8 \mu(19-26 \mu)$ $\mathrm{E}=16.6 \mu(15-19 \mu)$. FV: árbol. Ejemplar: E. Martínez S. 27573. Geol. a409.

Desmodium glabrum (Mill.) DC. Lám. 7:50a-50b Abertura: Tricolporado rara vez tetracolporado. Colpo meridional largo de $22.7 \mu$, colpo membrana lisa, colpo transversal lalongado rectangular de $3.8 \times 14.8 \mu$. Área polar grande (0.51). Exina: Tectada, psilada, patrón microreticulado. Exina de $2.5 \mu$ de espesor. Sex 1.5; Nex 1. ASP: Mónada; isopolar; radiosimétrico. Forma: Suboblado; CP: semiconvexa; CE: elíptico. Tamaño: $\mathrm{P}=37.3 \mu(33-41 \mu)$ $\mathrm{E}=42.3 \mu(36-45 \mu)$. FV: hierba. Ejemplar: Celso Gutiérrez B. 5116. Geol. a557.

Gliricidia maculata (Kunth) Walp.

Lám. 8:51

Abertura: Tricolporado. Colpo meridional largo de 25 $\times 2 \mu$, colpo membrana liso, colpo transversal reducido a un endoporo de 4-7 $\mu$. Área polar mediana (0.36). Exina: Tectada, psilada con patrón microreticulado. Exina de $2 \mu$ de espesor. Sex 2; Nex 1. ASP: Mónada, isopolar; radiosimétrica. Forma: Subprolado; CP: semiconvexa; CE: elíptico. Tamaño: $\mathrm{P}=35.3 \mu(31-39 \mu) \mathrm{E}=27 \mu(21-33 \mu)$. FV: árbol. Ejemplar: E. Martínez S. 35431. Geol. a424.

\section{Lonchocarpus castilloi Standl.}

Lám. 8:52a-52b

Abertura: Tricolporado. Colpo meridional largo $(24 \mu) \mathrm{y}$ estrecho en la parte central, colpo membrana microreticulada, colpo transversal con constricción central de $4 \times 6-7$ $\mu$. Área polar mediana (0.41). Exina: Tectada, psilada con patrón microreticulado. Exina de $2 \mu$ de espesor. Sex 2; Nex 1. ASP: Mónada, isopolar; radiosimétrica. Forma: Subprolado; CP: semiangular; CE: elíptico. Tamaño: $\mathrm{P}=27.9 \mu$ $(25-31 \mu) \mathrm{E}=23.7 \mu(22-25 \mu)$. FV: árbol. Ejemplar: P. Zamora C. y D. Méndez D. 5638. Geol. a429.

Lonchocarpus guatemalensis Benth. Lám. 8:53a-53b Abertura: Tricolporado. Colpo meridional de $27 \times 3 \mu$, colpo membrana microreticulada, colpo transversal reducido a un endoporo de $6.5 \mu$. Área polar mediana (0.35). Exina: Tectada, psilada con patrón microreticulado. Exina de $2 \mu$ de espesor. Sex 2; Nex 1. ASP: Mónada; isopolar; radiosimétrica. Forma: Prolado; CP: semiangular; CE: elíptico. Tamaño: $\mathrm{P}=32.4 \mu(29-38 \mu) \mathrm{E}=24.3 \mu(20-28$ $\mu$ ). FV: árbol. Ejemplar: Celso Gutiérrez B. 5100. Geol. a430.
Lonchocarpus hondurensis Benth. ～Lám. 8:54a-54b Abertura: Tricolporado. Colpo meridional largo de $23 \times 2$ $\mu$, colpo membrana microreticulada, colpo transversal con constricción central de $6.2 \mu$. Área polar mediana (0.27). Exina: Tectada, psilada con patrón microreticulado. Exina de $2 \mu$ de espesor. Sex 2; Nex 1. ASP: Mónada; isopolar; radiosimétrica. Forma: Subprolado; CP: semiangular; CE: elíptico. Tamaño: $\mathrm{P}=27.2 \mu(25-29 \mu) \mathrm{E}=22.5 \mu(20-25$ $\mu$ ). FV: árbol o arbusto. Ejemplar: C. Gutiérrez B. 5110. Geol. a431.

Lonchocarpus longistylus Pittier Lám. 8:55 Abertura: Tricolporado. Colpo meridional largo de $24 \times$ $2 \mu$, colpo membrana microreticulado, colpo transversal lalongado de $6.4 \mu$. Área polar mediana (0.37). Exina: Tectada, psilada con patrón microreticulado, Exina de $2 \mu$ de espesor. Sex 1; Nex 1. ASP: Mónada; isopolar; radiosimétrica. Forma: Subprolado; CP: semiangular; CE: elíptico. Tamaño: $\mathrm{P}=30.5 \mu(29-32 \mu) \mathrm{E}=25.8 \mu(21-29 \mu)$. FV: árbol. Ejemplar: E. Ucan 4260. Geol. a432.

\section{MALVACEAE}

Malvaviscus arboreus Cav. Lám. 8:56

Abertura: Periporada. Poros de $4 \mu$. Exina: Tectada, patrón microreticulado, supraequinada, espinas rombas, distancia entre espinas de $27 \mu$. Exina de $13 \mu$ de espesor. Sex 5; Nex 8. ASP: Mónada, apolar; radiosimétrica. Forma: Esferoidal. Tamaño: $\mathrm{D}=210.6 \mu(190-241 \mu)$. FV: arbusto. Ejemplar: Demetrio Álvarez 2253. Geol. a560.

\section{MELIACEAE}

Swietenia macrophylla King

Lám. 9:57

Abertura: Tetracolporado, colpo meridional largo de $21 \times$ $2 \mu$, colpo transversal rectangular $(2-3 \times 4-5 \mu)$. Área polar mediana (0.30). Exina: Tectada, psilada. Exina de $2 \mu$ de espesor. Sex 2; Nex 1. ASP: Mónada, isopolar; radiosimétrica. Forma: Prolado esferoidal; CP: circular; CE: elíptico. Tamaño: $\mathrm{P}=31.9 \mu(27-35 \mu) \mathrm{E}=28.6 \mu(25-38 \mu)$. FV: árbol. Ejemplar: J. I. Calzada 6859. Geol. a454.

Trichilia arborea C. DC.

Lám. 9:58a-58b

Abertura: Tetracolporado o pentacolporado. Colpo meridional largo de $27 \times 2-3 \mu$, colpos membrana lisa, colpo transversal lalongado circular de $5 \mu$. Área polar mediana (0.27). Exina: Tectada, psilada. Exina de $2 \mu$ de espesor. Sex 2; Nex 1. ASP: Mónada, isopolar; radiosimétrica. Forma: Prolado esferoidal; CP: circular; CE: elíptico-circular. Tamaño: $\mathrm{P}=37.4 \mu(32-42 \mu) \mathrm{E}=33 \mu(28-38 \mu)$. FV: árbol. Ejemplar: Ma. Guadalupe Ayala 9151. Geol. a455.

Trichilia havanensis Jacq.

Lám. 9:59a-59b

Abertura: Tetracolporado o pentacolporado. Colpo meridional largo de $27 \times 2 \mu$, colpo membrana lisa, colpo transversal elíptico circular de 3-4 × 5-7 $\mu$. Área polar mediana 


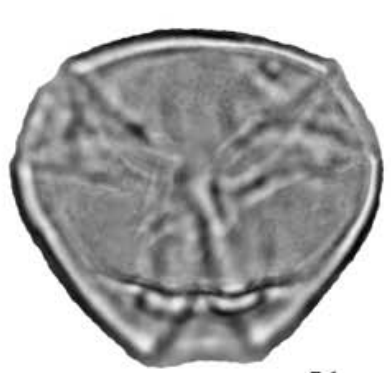

51

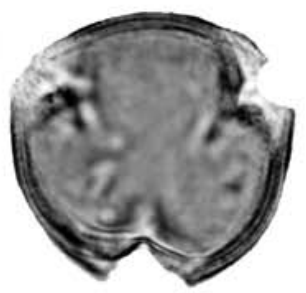

$52 \mathrm{a}$
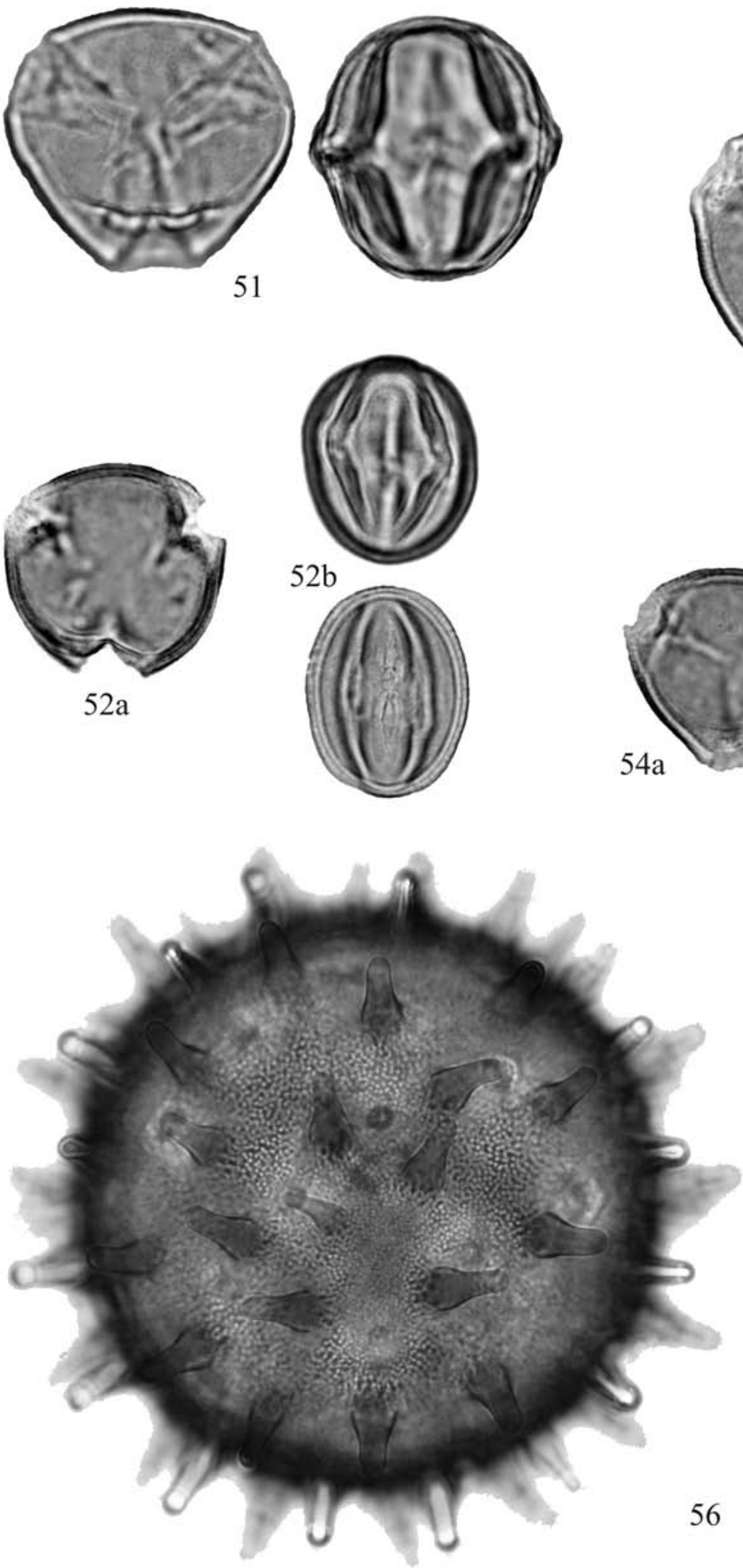

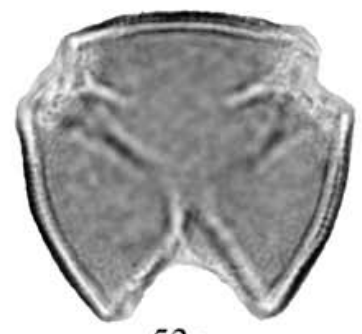

$53 a$
LAMINA 8
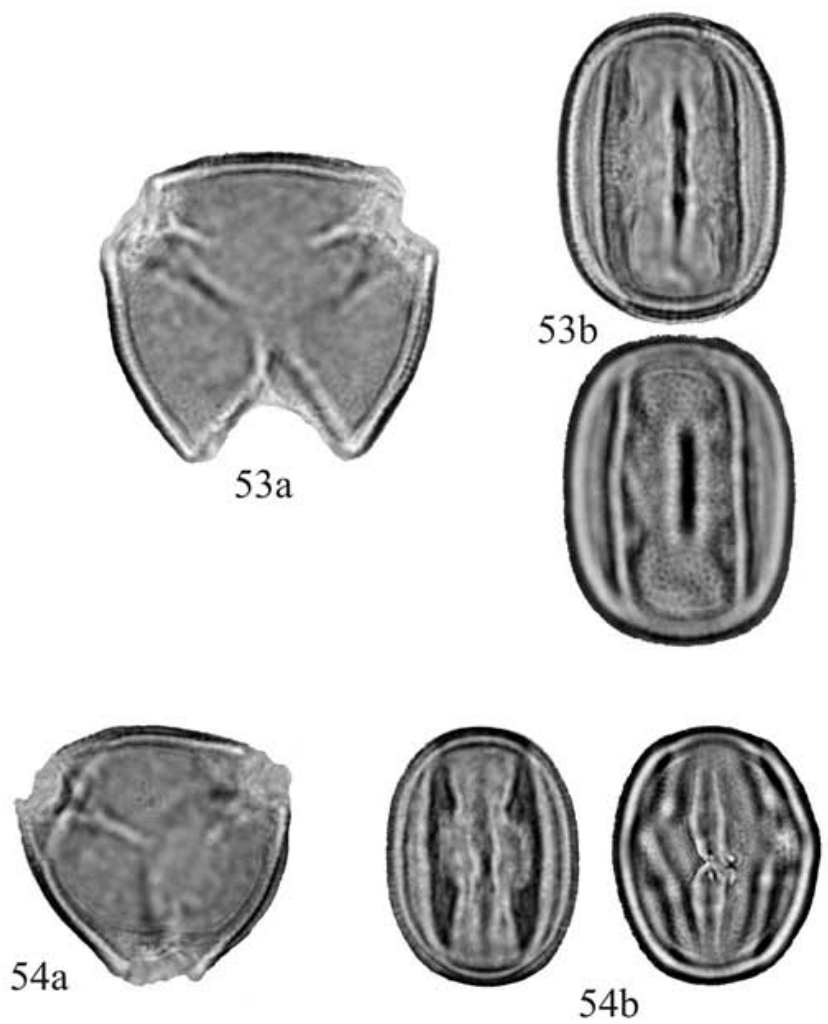

$54 \mathrm{~b}$
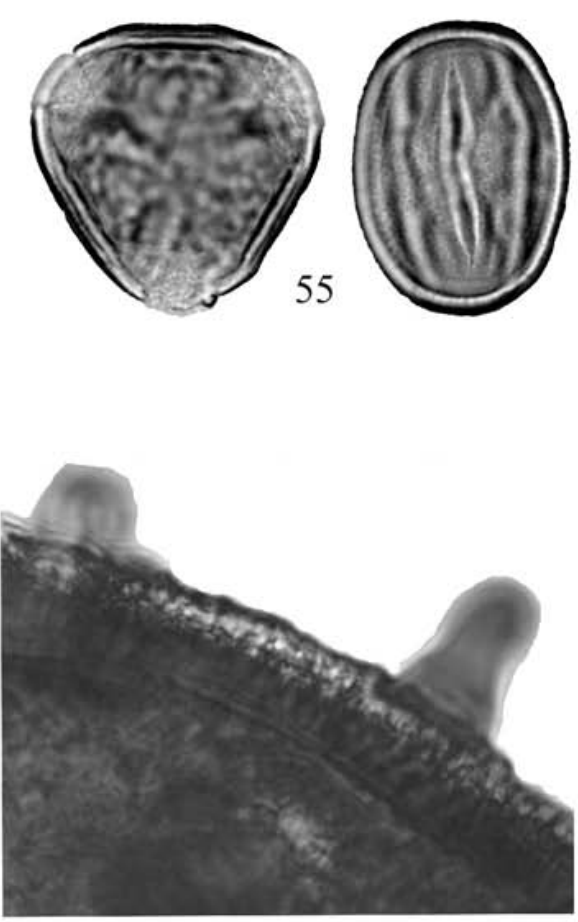

LAMINA 8. LEGUMINOSAE. PAPILIONOIDEAE: Gliricidia maculata (51: vista polar y ecuatorial) (1000x); Lonchocarpus castilloi (52a: vista polar; 52b: vista ecuatorial) (1000x); Lonchocarpus guatemalensis (53a: vista polar; 53b: vista ecuatorial) (1000x); Lonchocarpus hondurensis (54a: vista polar; 54b: vista ecuatorial) (1000x); Lonchocarpus longistylus (55: vista polar y ecuatorial) (1000x); MALVACEAE: Malvaviscus arboreus (56: ornamentación y corte óptico) (500x y 250x). 
(0.27). Exina: Tectada, psilada con patrón microreticulado. Exina de $2 \mu$ de espesor. Sex 2; Nex 1. ASP: Mónada, isopolar; radiosimétrica. Forma: Prolado esferoidal; $\mathrm{CP}$ : circular; CE: elíptico-circular. Tamaño: $\mathrm{P}=34.7 \mu(30-40 \mu)$ $\mathrm{E}=32.5 \mu(27-38 \mu)$. FV: árbol. Ejemplar: Celso Gutiérrez B. 5176. Geol. a456.

\section{Trichilia hirta L.}

Lám. 9:60

Abertura: Tetracolporado. Colpo meridional largo de $27 \times 1$ $\mu$, colpo membrana lisa, colpo transversal lalongado elípticocircular de 3-4 × 6-10 $\mu$. Área polar mediana (0.29). Exina: Tectada, psilada con patrón microreticulado. Exina de $2 \mu$ de espesor. Sex 2; Nex 1. ASP: Mónada, isopolar; radiosimétrica. Forma: Prolado esferoidal; CP: circular; CE: elíptico. Tamaño: $\mathrm{P}=38 \mu(33-41 \mu) \mathrm{E}=33.7 \mu(28-39 \mu)$. FV: árbol. Ejemplar: Celso Gutiérrez B. 5254. Geol. a457.

\section{Trichilia minutiflora Standl.}

Lám. 9:61

Abertura: Tricolporado rara vez tetracolporado. Colpo meridional largo de $22 \times 2 \mu$, colpo transversal lalongado elíptico-circular de 2-4 × 5-6 $\mu$. Área polar mediana (0.33). Exina: Tectada, psilada con patrón microreticulado. Exina de $2 \mu$ de espesor. Sex 2; Nex 1. ASP: Mónada, isopolar; radiosimétrica. Forma: Subprolado; CP: semiangular; CE: elíptico. Tamaño: $\mathrm{P}=26.1 \mu(23-30 \mu) \mathrm{E}=22.6 \mu(20-25 \mu)$. FV: árbol. Ejemplar: D. Álvarez D. 4999. Geol. a458.

\section{Trichilia moschata Sw.}

Lám. 9:62

Abertura: Tricolporado rara vez tetracolporado. Colpo meridional largo de $21 \times 2 \mu$, colpo transversal lalongado elíptico-circular de 4-5 × 6-8 $\mu$. Margo de $3 \mu$. Área polar mediana (0.45). Exina: Tectada, psilada con patrón microreticulado. Exina de $2 \mu$ de espesor. Sex 2; Nex 1. ASP: Mónada, isopolar; radiosimétrica. Forma: Oblado esferoidal; CP: circular; CE: circular. Tamaño: $\mathrm{P}=31.5 \mu(28-35$ $\mu) \mathrm{E}=31.8 \mu(28-37 \mu)$. FV: árbol. Ejemplar: D. Álvarez D. 4961. Geol. a459.

\section{MORACEAE}

Cecropia obtusifolia Bertol.

Lám. 9:63

Abertura: Diporado. Poro de $2.5 \mu$ de diámetro, anillo de $1 \mu$. Exina: Tectada, supramicroescabrada. Exina de $1 \mu$ de espesor. Sexina y nexina difícil de observar. ASP: Mónada, isopolar; bilateral. Forma: Prolado; CP: elíptico; CE: elíptico. Tamaño: $\mathrm{P}=13.4 \mu(11-17 \mu) \mathrm{E}=8.3 \mu(7-10 \mu)$. FV: árbol. Ejemplar: E. Martínez S. 7004. Geol. a460.

\section{Ficus obtusifolia Kunth}

Lám. 9:64

Abertura: Diporado rara vez triporado. Poro de $1.8 \mu$ de diámetro. Exina: Tectada, psilada con patrón microreticulado. Exina de $1 \mu$ de espesor. Sexina y nexina difícil de observar. ASP: Mónada, isopolar; bilateral o radiosimétrica. Forma: Oblada; CP: elíptico; CE: elíptico. Tamaño: $\mathrm{P}=9.7$ $\mu(6-12 \mu) \mathrm{E}=14.7 \mu(7-16 \mu)$. FV: árbol. Ejemplar: $\mathrm{G}$.
Carnevali, J. L. Tapia, F. May, M. Gómez, R. Jiménez y L. Sánchez 5307. Geol. a462.

Ficus pertusa L. f. Lám. 10:65

Abertura: Diporado. Poro de $1.4 \mu$ de diámetro. Exina: Tectada, psilada con patrón microreticulado. Exina de $1 \mu$ de espesor. Sexina y nexina difícil de observar. ASP: Mónada, isopolar; bilateral. Forma: Oblada; CP: elíptico; CE: elíptico. Tamaño: $\mathrm{P}=9.6 \mu(8-11 \mu) \mathrm{E}=15 \mu(13-17 \mu)$. FV: árbol. Ejemplar: Celso Gutiérrez B. 4366. Geol. a463.

Trophis racemosa (L.) Urb. Lám. 10:66 Abertura: Diporado rara vez triporado. Poro de $2.5 \mu$ de diámetro, anillo de $1 \mu$. Exina: Tectada, escabrada. Exina de $1 \mu$ de espesor. Sexina y nexina difícil de observar. ASP: Mónada, isopolar; bilateral. Forma: Prolado esferoidal; CP: circular; CE: elíptico. Tamaño: $\mathrm{P}=18 \mu(16-20 \mu) \mathrm{E}=17.1$ $\mu(16-20 \mu)$. FV: árbol. Geol. a464.

\section{NYCTAGINACEAE}

\section{Boerhavia erecta L.}

Lám. 10:67

Abertura: Periporada. Poros de $5 \mu$ y anillo de $1 \mu$. Exina: Tectada, supraequinada, espinas de $5 \mu$. Exina de $5.3 \mu$ de espesor. Sex 3; Nex 2. ASP: Mónada; apolar; radiosimétrica. Forma: Esferoidal. Tamaño: D: $89.9 \mu(81-105 \mu)$. FV: hierba. Ejemplar: P. Zamora C. 4486. Geol. a562.

\section{POACEAE}

Cynodon dactylon (L.) Pers. Lám. 10:68

Abertura: Monoporado o diporado, rara vez triporado. Poros circulares de $4.7 \mu$ de diámetro, anillo de $1 \mu$. Exina: Tectada, psilada, supramicroescabrada con patrón microreticulado. Exina de $2 \mu$ de espesor. Sex 1; Nex 1. ASP: Mónada; isopolar o heteropolar; bilateral. Forma: Oblado esferoidal; CP: circular; CE: circular. Tamaño: $\mathrm{P}=42.2 \mu$ $(38-47 \mu) \mathrm{E}=43.3 \mu(39-47 \mu)$. FV: hierba. Ejemplar: Celso Gutiérrez B.y J. Balam 6472. Geol. a554.

Panicum laxum Sw.

Lám. 10:69

Abertura: Monoporado o diporado, rara vez triporado. Poros circulares de $3 \mu$ de diámetro. Exina: Tectada, psilada con patrón microreticulado. Exina de $3 \mu$ de espesor. Sex 2; Nex 1. ASP: Mónada; isopolar o heteropolar; bilateral. Forma: Oblado esferoidal; CP: circular; CE: circular. Tamaño: $\mathrm{P}=28.6 \mu(24-36 \mu) \mathrm{E}=28.9 \mu(25-36 \mu)$. FV: hierba. Ejemplar: J. J. Ortiz y M. Magaña 2324. Geol. a555

Paspalum plicatulum Michx. Lám. 10:70

Abertura: Monoporado. Poro circular de $6.5 \mu$ de diámetro con un anillo de $1 \mu$. Exina: Tectada, psilada con patrón microreticulado. Exina de $2 \mu$ de espesor. Sex 1; Nex 1. ASP: Mónada; heteropolar. Forma: Oblado. Tamaño: $\mathrm{D}=83 \mu$ (77-95 $\mu$ ). FV: hierba. Ejemplar: J. J. Ortiz e I. Miranda 2296. Geol. a556. 


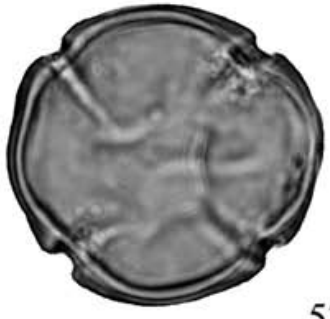

57
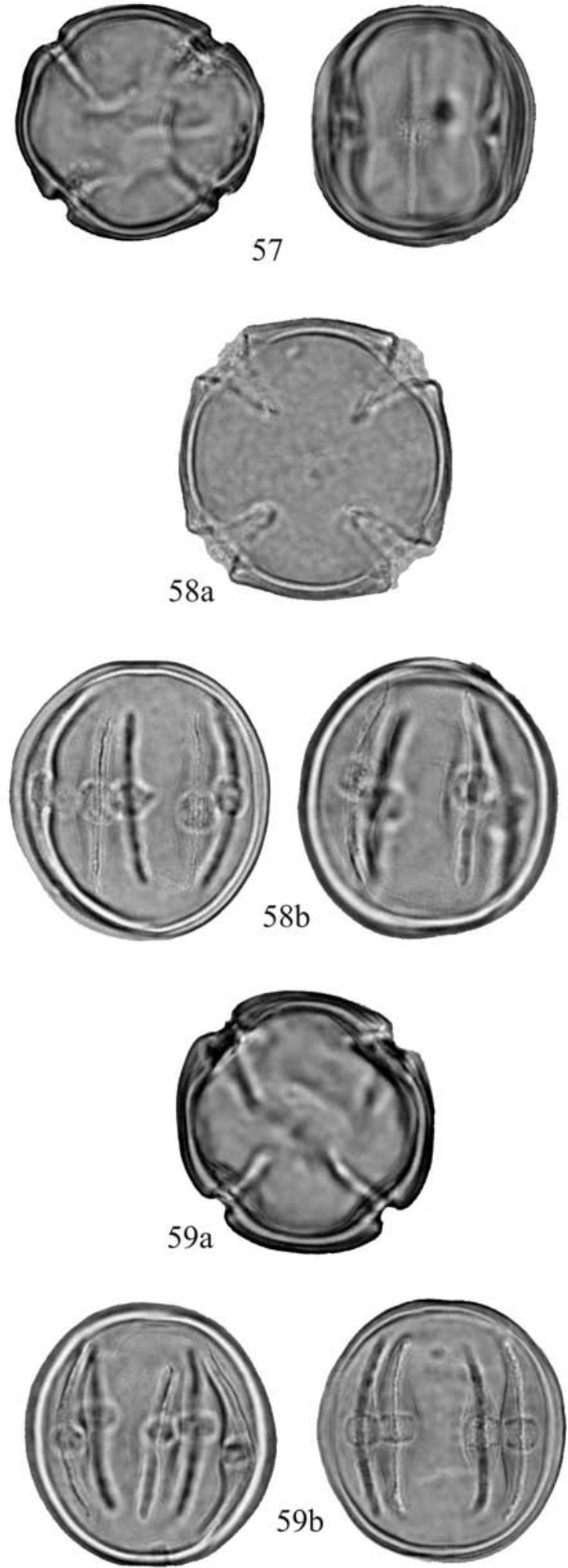

LAMINA 9
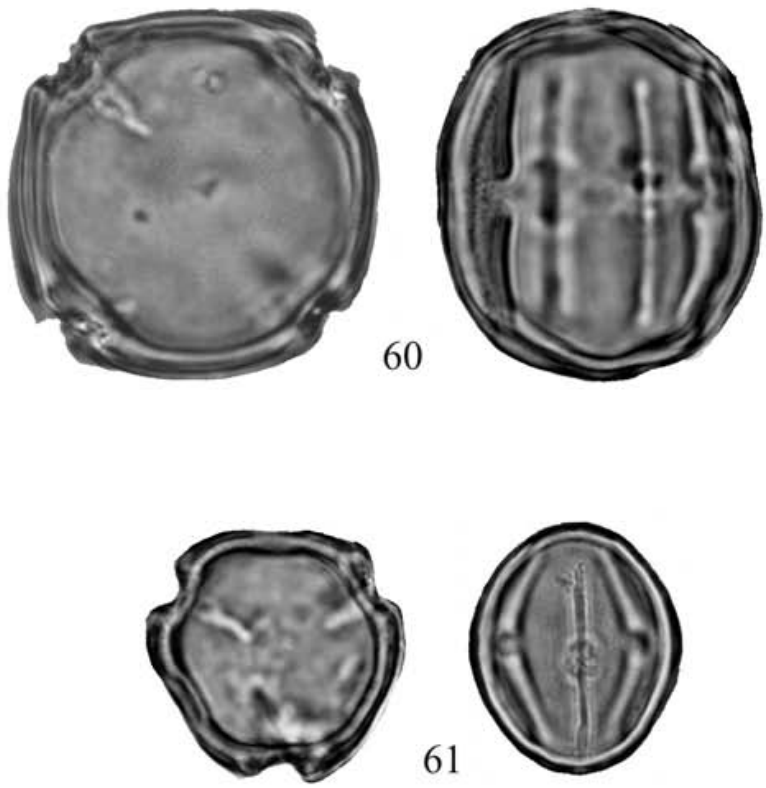

61
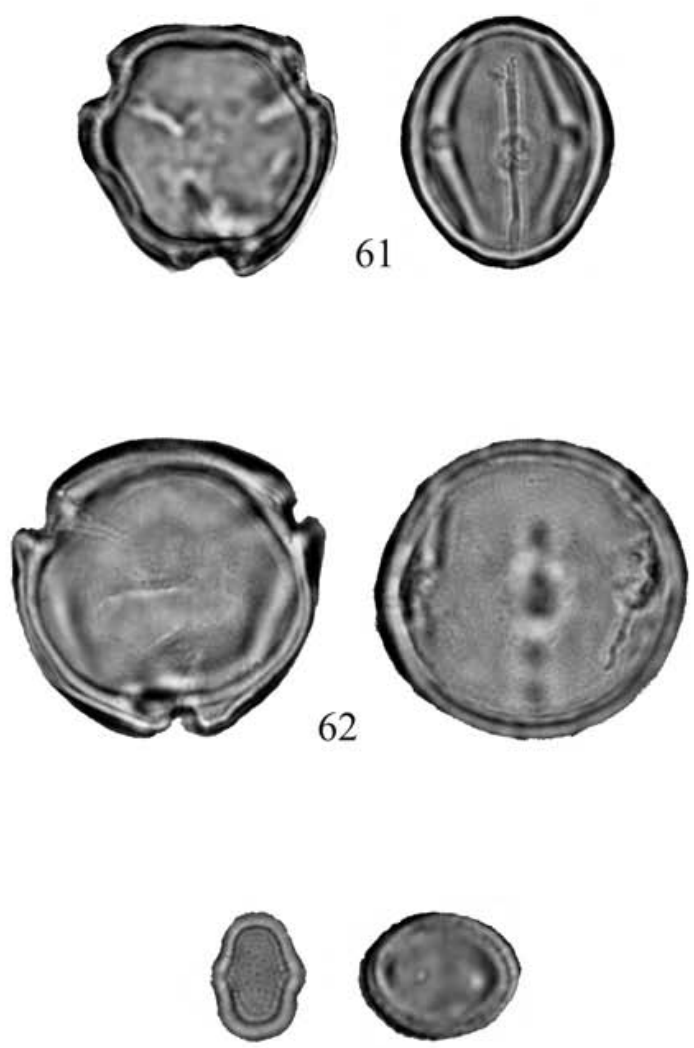

63
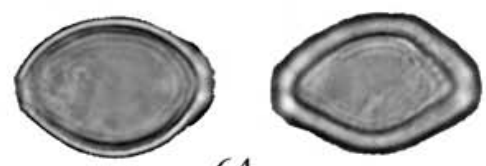

64

LAMINA 9. MELIACEAE: Swietenia macrophylla (57: vista polar y ecuatorial) (1000x); Trichilia arborea (58a: vista polar; 58b: vista ecuatorial y ornamentación) (1000x); Trichilia havanensis (59a: vista polar; 59b: vista ecuatorial y ornamentación) (1000x); Trichilia hirta (60: vista polar y ecuatorial) (1000x); Trichilia minutiflora (61: vista polar y ecuatorial) (1000x); Trichilia moschata (62: vista polar y ecuatorial) (1000x); MORACEAE: Cecropia obtusifolia (63: vista ecuatorial y corte óptico) (1000x); Ficus obtusifolia (64: vista polar y ornamentación) (1000x). 


\section{POLYGONACEAE}

Coccoloba reflexiflora Standl.

Lám. 10:71

Abertura: Tricolporado. Colpo meridional largo de $37 \times 1$ $\mu$, colpo transversal lalongado de 2-3 $\times 4 \mu$. Margo de 3.5 $\mu$. Área polar grande (0.61). Exina: Tectada, escrobiculada. Exina de $\mu 2.4$ de espesor. Sex 2; Nex 1. ASP: Mónada, isopolar; radiosimétrica. Forma: Prolado; CP: semiconvexa; CE: elíptico. Tamaño: $\mathrm{P}=46 \mu(39-54 \mu) \mathrm{E}=34 \mu(28-49 \mu)$. FV: árbol. Ejemplar: E. Martínez S. 27581. Geol. a238.

\section{Neomillspaughia emarginata}

Lám. 10:72

(H. Gross.) S.F.Blake

Abertura: Tricolporado. Colpo meridional largo de $29 \times 2$ $\mu$, colpo transversal lalongado de $2 \times 4 \mu$. Área polar pequeña (0.16). Exina: Subtectada, microreticulada. Exina de $2 \mu$ de espesor. ASP: Mónada, isopolar; radiosimétrica. Forma: Prolado; CP: semiconvexa; CE: elíptico. Tamaño: P=36.9 $\mu(31-42 \mu) \mathrm{E}=26.4$ _ $(22-30 \mu)$. FV: árbol o arbusto. Ejemplar: J. Calónico Soto 4333. Geol. a239.

\section{RUBIACEAE}

Randia longiloba Hemsl.

Lám. 11:73

Abertura: Tétrada triporada. Poros de 2-4 $\mu$. Anillo de 1.5 $\mu$. Exina: Tectada, psilada. Exina de $2 \mu$ de espesor. ASP: Mónada, isopolar; radiosimétrica. Forma: Tetrada tetraédrica. Tamaño: $\mathrm{P}=35 \mu(29-46 \mu) \mathrm{E}=28.1 \mu(20-39 \mu)$. FV: árbol o arbusto. Ejemplar: Celso Gutiérrez B. 5172. Geol. a242.

\section{SAPINDACEAE}

Talisia floresii Standl.

Lám. 11:74

Abertura: Tricolporado. Colpo meridional largo de $21 \times$ $4 \mu$, colpo membrana lisa, colpo transversal lolongado de $3 \times 6 \mu$. Margo de $2 \mu$. Área polar mediana (0.28). Exina: Tectada, psilada con patrón microreticulado. Exina de $2 \mu$ de espesor. Sex 2; Nex 1. ASP: Mónada, isopolar; radiosimétrica. Forma: Oblado esferoidal; CP: semiangular; CE: elíptico-circular. Tamaño: $\mathrm{P}=25.7 \mu(22-32 \mu) \mathrm{E}=26.5 \mu$ (24-31 $\mu$ ). FV: árbol. Ejemplar: J. Calónico Soto 23664. Geol. a471.

Thinouia paucidentata Radlkofer Lám. 11:75

Abertura: Triporado. Poros de 3-4 $\mu$ de diámetro. Anillo de $2 \mu$. Exina: Subtectada, reticulada, heterobrocada. Exina de $2 \mu$ de espesor. Sex 1; Nex 1. ASP: Mónada, isopolar; radiosimétrica. Forma: Suboblado; CP: convexa; CE: elíptico. Tamaño: $\mathrm{P}=19.4 \mu(18-22 \mu) \mathrm{E}=23.5 \mu(22-28 \mu)$. FV: árbol. Ejemplar: M. Consuelo Sánchez G. 322. Geol. a244.

\section{SAPOTACEAE}

Pouteria amygdalina (Standl.) Baehni Lám. 11:76 Abertura: Tricolporado. Colpo meridional largo de $19 \times$ $2 \mu$, colpo transversal lalongado rectangular de $2 \times 4 \mu$, se observa un vestíbulo a nivel del colpo transversal. Área polar mediana (0.36). Exina: Tectada, psilada con patrón microreticulado. Exina de $2 \mu$ de espesor. Sex 2; Nex 1. ASP: Mónada, isopolar; radiosimétrica. Forma: Prolado; CP: semiconvexa CE: elíptico. Tamaño: $\mathrm{P}=28 \mu(26-30 \mu)$ $\mathrm{E}=19.6 \mu(16-23 \mu)$. FV: árbol. Ejemplar: E. Martínez S., D. Álvarez D. y P. Alvaro M. 27190. Geol. a475.

Pouteria reticulata (Engl.) Eyma Lám. 11:77

Abertura: Tricolporado. Colpo meridional largo de $21 \times 2$ $\mu$, colpo transversal lalongado rectangular de $3 \times 5 \mu$. Área polar mediana (0.31). Exina: Tectada, psilada con patrón microreticulado. Exina de $2 \mu$ de espesor. Sex 2; Nex 1. ASP: Mónada, isopolar; radiosimétrica. Forma: Subprolado; CP: semiangular; CE: elíptico. Tamaño: $\mathrm{P}=30 \mu$ (27-33 $\mu) \mathrm{E}=24.3 \mu(22-27 \mu)$. FV: árbol. Ejemplar: D. Mendez D. y Christopher B. 215. Geol. a477.

\section{SIMAROUBACEAE}

Simarouba glauca DC.

Lám. 11:78

Abertura: Tricolporado. Colpo meridional largo de $20 \times 2$ $\mu$, colpo transversal rectangular de 3-4 × 5-6 $\mu$. Área polar mediana (0.38). Exina: Tectada, psilada con patrón microreticulado. Exina de $2 \mu$ de espesor. ASP: Mónada, isopolar; radiosimétrica. Forma: Prolado; CP: semiangular; CE: elíptico. Tamaño: $\mathrm{P}=28.1 \mu(27-32 \mu) \mathrm{E}=18 \mu(17-20 \mu)$. FV: árbol. Ejemplar: D. Álvarez D. 1169. Geol. a246.

\section{TILIACEAE}

Heliocarpus donnellsmithii Rose Lám. 11:79

Abertura: Tricolporado. Colpo meridional largo de $32 \times 3$ $\mu$, colpo transversal lalongado de $3 \times 4 \mu$. Área polar mediana (0.45). Exina: Subtectada, suprareticulada, heterobrocada. Exina de $2.5 \mu$ de espesor. Sex 2; Nex 1. ASP: Mónada, isopolar; radiosimétrica. Forma: Prolado; CE: elíptico. Tamaño: $\mathrm{P}=44 \mu(42-44 \mu) \mathrm{E}=32 \mu(30-33 \mu)$. FV: árbol o arbusto. Ejemplar revisado: C. Chan 4667. Geol. a449.

\section{Luehea candida}

(Moc. \& Sessé ex DC.) Mart. Lám. 11:80

Abertura: Tricolporado. Colpo meridional largo de $45 \times 2$ $\mu$, colpo membrana lisa, colpo transversal lalongado rectangular de $2 \times 4 \mu$. Área polar grande (0.53). Exina: Subtectada, suprareticulada, heterobrocada. Exina de $2 \mu$ de espesor. Sex 2; Nex 1. ASP: Mónada, isopolar; radiosimétrica. Forma: Subprolado; CP: circular; CE: elíptico. Tamaño: P= $61.6 \mu(55-77 \mu) \mathrm{E}=53.3 \mu(48-60 \mu)$. FV: árbol. Ejemplar revisado: J. I. Calzada 7679. Geol. a451.

\section{VERBENACEAE}

Stachytarpheta jamaicensis (L.) Vahl Lám. 11:81

Abertura: Tricolpado. Colpos largos de $109.4 \mu$. Área polar mediana (0.49). Exina: Tectada, verrugada, verrugas de $6 \times$ $6.5 \mu$. Exina de $5 \mu$. Sex 3; Nex 2. ASP: Mónada; isopolar; radiosimetrica. Forma: Subprolado; CP: semiconvexa; CE: 

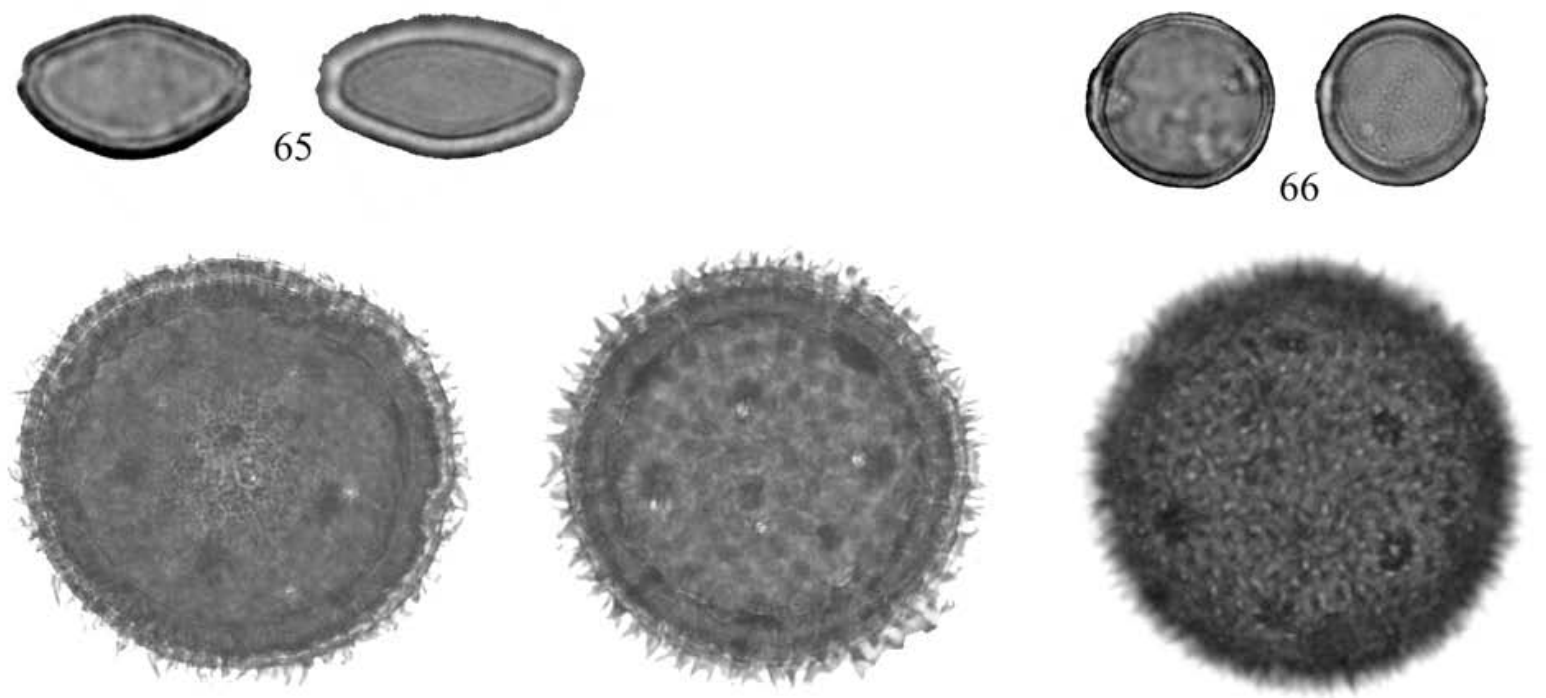

67
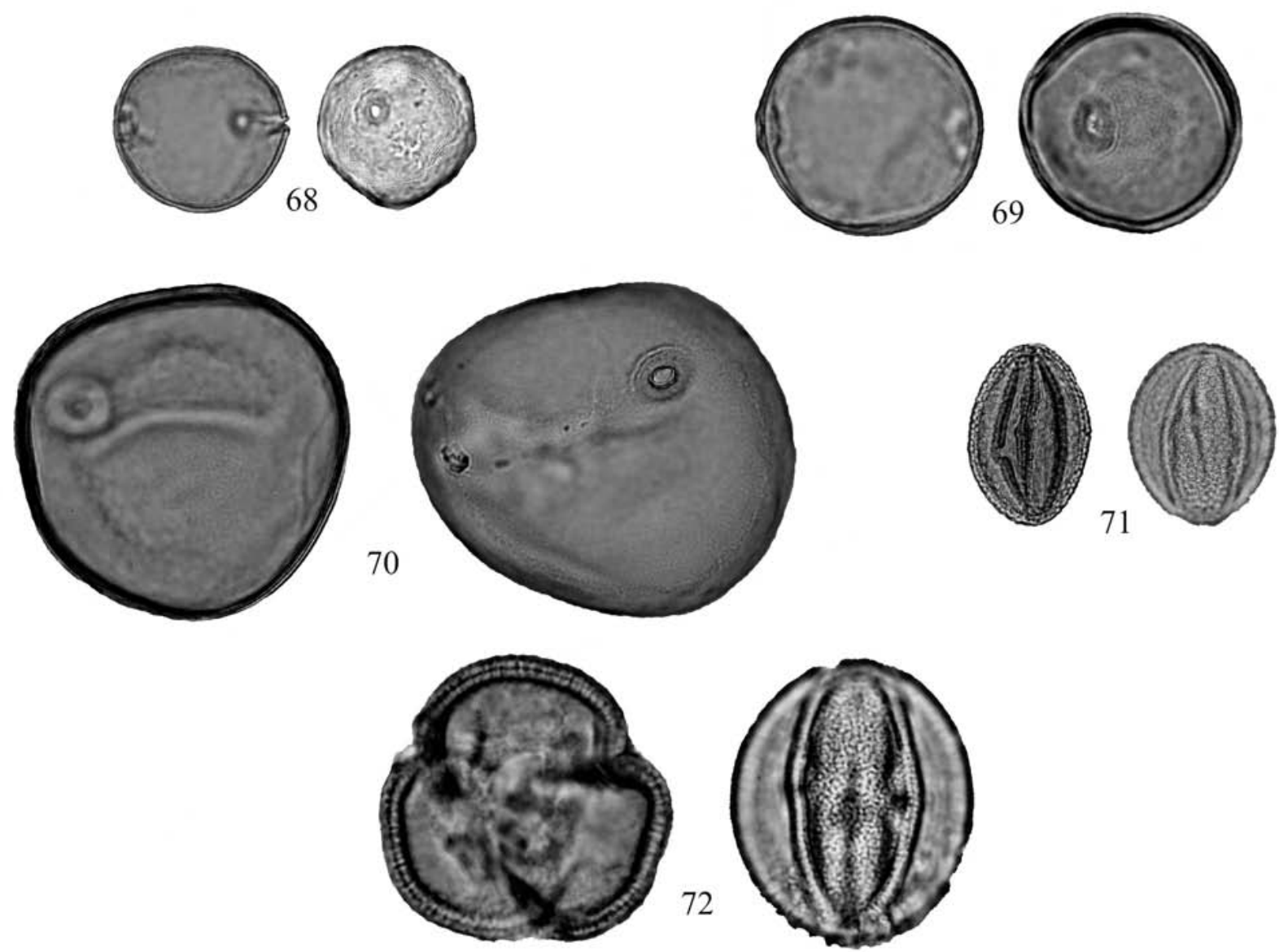

LAMINA 10. MORACEAE: Ficus pertusa (65: vista polar y ornamentación) (1000x); Trophis racemosa (66: vista polar y ornamentación) (1000x); NYCTAGINACEAE: Boerhavia erecta (67: corte óptico y ornamentación)(500x); POACEAE: Cynodon dactylon (68: vista polar y ecuatorial) (500x); Panicum laxum (69: vista polar y ecuatorial) (1000x); Paspalum plicatulum (70: corte óptico y ornamentación) (500x); POLYGONACEAE: Coccoloba reflexiflora (71: vista ecuatorial y ornamentación) (500x); Neomillispaughia emarginata (72: vista polar y ecuatorial) (1000x). 

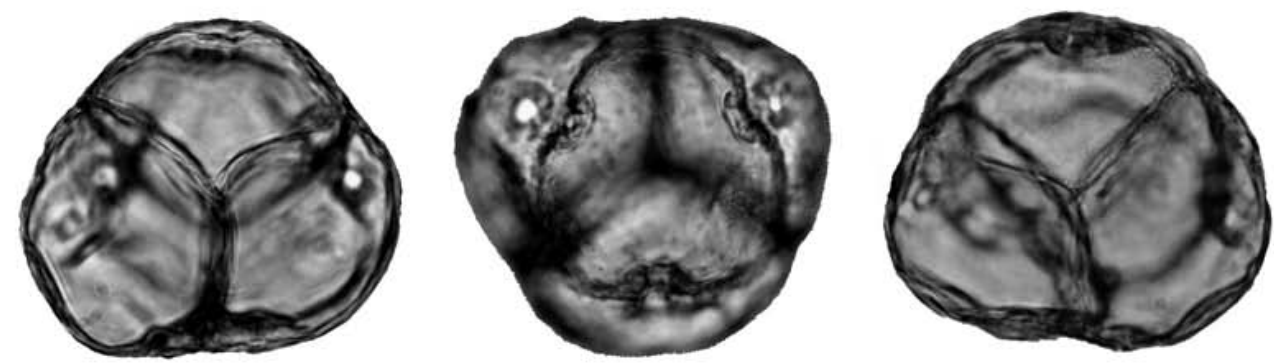

\section{LAMINA 11}

73
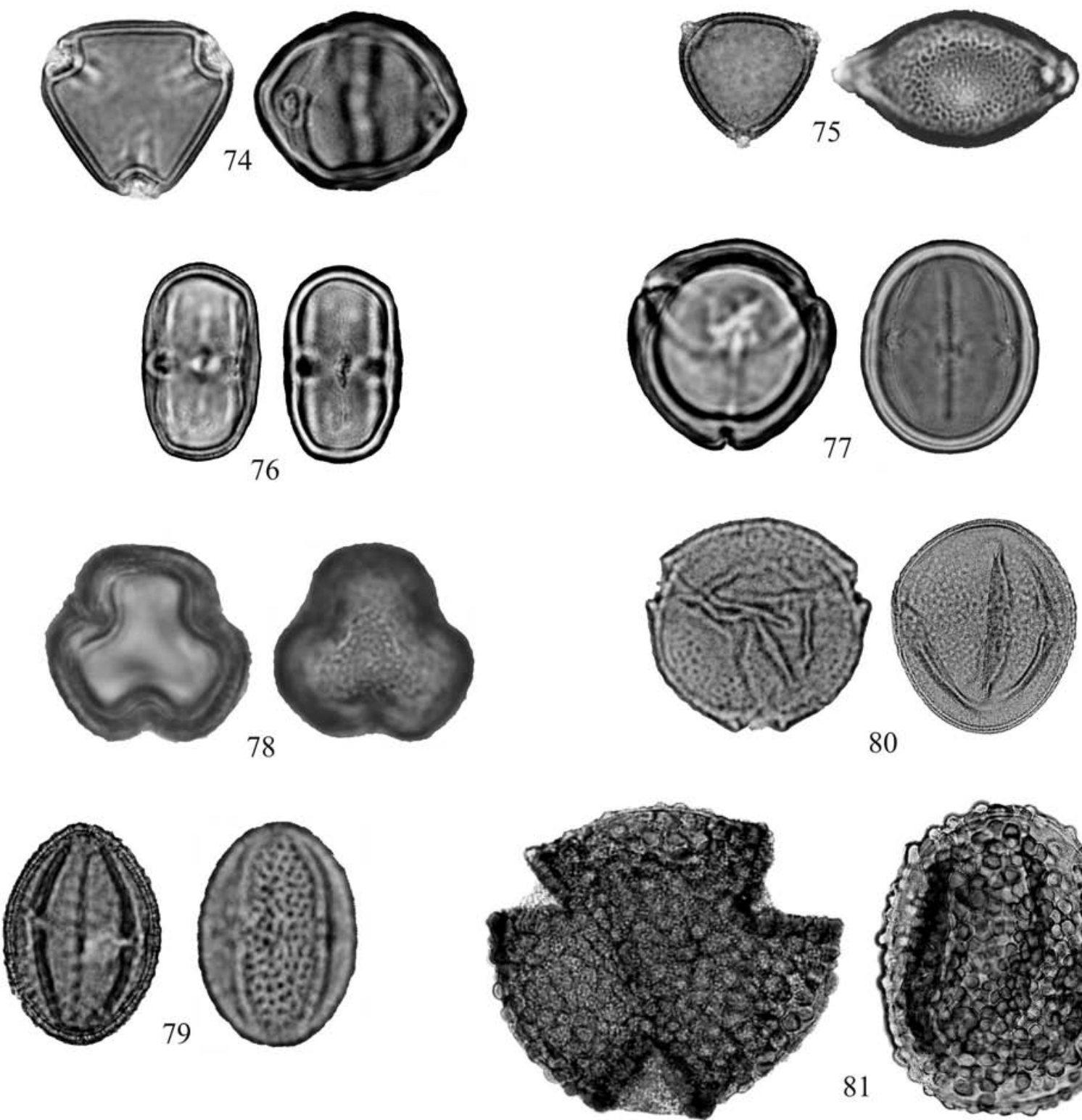

80

81

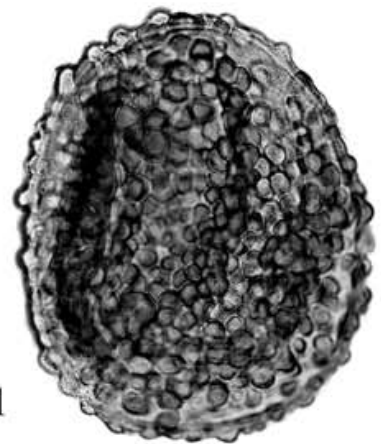

LAMINA 11. RUBIACEAE: Randia longiloba (73: vista polar y ornamentación) (1000x); SAPINDACEAE: Talisia floresii (74: vista polar y ecuatorial) (1000x); Thinouia paucidentata (75: vista polar y ecuatorial) (1000x); SAPOTACEAE: Pouteria amygdalina (76: vista ecuatorial y ornamentación) (1000x); Pouteria reticulata (77: vista polar y ecuatorial) (1000x); SIMAROUBACEAE: Simarouba glauca (78: vista polar y ornamentación) (1000x); TILIACEAE: Heliocarpus donnell-smithii (79: vista ecuatorial y ornamentación) (1000x); Luehea candida (80: vista polar y ecuatorial) (500x); VERBENACEAE: Stachytarpheta jamaicensis (81: vista polar y ecuatorial) (500x). 
elíptico. Tamaño: $\mathrm{P}=121.5 \mu(90-139 \mu) \mathrm{E}=97.3 \mu(80-108$ $\mu$ ). FV: hierba. Ejemplar: P. Zamora C. 5149. Geol. a564.

\section{Discusión}

Dada la amplia diversidad de las comunidades tropicales en México, es importante documentar, a través de floras polínicas, la morfología de las distintas especies que las conforman. En este estudio se describen por primera vez para la zona, la morfología polínica de 81 especies de la selva mediana subperennifolia de la cuenca de río Candelaria correspondientes a 29 familias. Las investigaciones paleoecológicas basadas en el análisis del contenido de polen en sedimentos de diferentes cuerpos de agua de la península de Yucatán, han aportado datos sobre el impacto de los cambios climáticos y ambientales en la vegetación durante los últimos cientos de años (Leyden, 2002). Siendo el análisis de polen la herramienta para la reconstrucción de la historia de la vegetación, los conjuntos polínicos fósiles de zonas tropicales muestran que los granos de polen no son identificados a nivel específico, lo que lleva a la perdida de información en las reconstrucciones paleo-ambientales. Una limitación importante para la correcta interpretación del impacto de las variaciones ambientales en la vegetación, ya sean climáticas y/o antropogénicas, es el conocimiento de la morfología polínica de las especies tropicales.

\section{Agradecimientos}

Al Dr. Jorge A. Benítez Torres del Centro de Ecología, Pesquería y Oceanografía del Golfo de México (EPOMEX) por su apoyo y contribución económica a través del proyecto "Sistema de Información Geográfica de la Cuenca del Río Candelaria: hacia un uso forestal sustentable y el entendimiento de los efectos de los cambios en la cobertura forestal sobre hidrología, calidad del agua y biodiversidad (CONAFOR- Centro EPOMEX de la Universidad Autónoma de Campeche (UAC). Al herbario UCAM del Centro de Investigaciones Históricas y Sociales de la Universidad Autónoma de Campeche y al Centro de Investigación Científica de Yucatán por los ejemplares proporcionados. Al Biol. Celso Gutiérrez y la M. en C. María C. Sánchez del herbario UCAM por su apoyo.

\section{Literatura citada}

Alvarado J.L. y Palacios-Chávez R. 1987. Catálogo palinológico para la flora de Veracruz No. 35 familia Marcgraviaceae. Biótica 12: 67-77.

Arellano-Rodríguez J.A., Flores J.S., Garrido J.T y Bojorquez M.M.C. 2003. Nomenclatura, forma de vida, uso manejo y distribución de las especies vegetales de la Península de Yucatán. Fascículo 20 de la Colección Etnoflora Yucatanense. Universidad Autónoma de Yucatán. Méx. 900 p.

Ayala-Nieto M.L. y Ludlow-Wiechers B. 1983. Catálogo palinológi- co para la Flora de Veracruz No. 13, familia Ebenaceae. Biótica 8: $215-226$.

Benítez T.J.A., Sánchez H.S., Contreras J.L., Zamora P.C., Manilla M.M., Caussel F.M., Gil G.G., Couturier S., Zetina R.T., Calán R.Y., Amabilis L.S., Acuña C.y Mejenes M. 2005. Sistema de Información Geográfica de la Cuenca del Río Candelaria: Reconstrucción histórica de los cambios en la cobertura forestal y su efecto sobre la hidrología y calidad del agua. En: Kauffer Michel E.F.Ed. El agua en la frontera México-GuatemalaBelice, pp. 19-32, El Colegio de la Frontera Sur. Universidad Autónoma de Chiapas, México.

Cronquist A. 1981. An integrated system of classification of flowering plants. Columbia University Press. Nueva York. 719 p.

Erdtman G. 1969. Handbook of Palynology: Morphology, taxonomy, ecology an introduction to the study of pollen grains and spores. Hafner Publishing Co. New York. 486p.

Flores G.J.S. 2001. Leguminosae: florística, etnobotánica $y$ ecología. Fascículo 18. Etnoflora Yucatanense Universidad Autónoma de Yucatán. Mérida, Yucatán, México. 320p.

Gómez-Pompa A. 1971. Posible papel de la vegetación secundaria en la evolución de la flora tropical. Biotropica 3:125-135.

Gutiérrez B.C. 2000. Listado florístico actualizado del estado de Campeche, México. Centro de Investigaciones Históricas y Sociales. Publicaciones de la Universidad Autónoma de Campeche. 95p.

Kremp G.O.W. 1965. Morphologic encyclopedia of palynology. University of Arizona Press. Tucson. 263p.

Leyden W.B. 2002. Pollen evidence for climatic variability and cultural disturbance in the Maya lowlands. Ancient Mesoamérica 13:85-101.

Lozano-García M.S. y Martínez-Hernández E. 1990. Palinología de los Tuxtlas: especies arbóreas. Universidad Nacional Autónoma de México. Instituto de Biología. Publicaciones Especiales No. 3. 61p.

Lozano-García M.S., Ibarra-Manríquez G. y Sosa-Nájera S. 1995. Palinología de las lianas de la Estación de Biología Tropical "Los Tuxtlas". Boletín Sociedad de la Botánica de México 57:79-102.

Lozano-García M.S., Sosa-Nájera M.S., Sugiura Y. y Caballero M. 2005. 23,000 years of vegetation history of the Upper Lerma, a tropical high-altitude basin in Central México. Quaternary Research 64:70-82.

Lozano-García M.S., Caballero M., Ortega B., Rodríguez A. y Sosa S. 2007. Tracing the effects of the little Ice Age in the tropical lowlands of eastern Mesoamerica. Proceedings of the National Academy of Sciences 104: 16200-16203.

Ludlow B.M.R. y Martínez-Hernández E. 1983. Morfología del polen de las Nyctaginaceae de México. Biótica 8: 107-148.

Macías C.A. y del Amo S.R. 2002. Caracterización del manejo forestal en el ejido de Xkan-Ha, Campeche, bajo el concepto de integridad. Sociedades Rurales, Producción y Medio Ambiente 3:18-29.

Martínez E., Sousa M. y Ramos A.C.H. 2001. Listados Florísticos de México XXII. Región de Calakmul, Campeche, pp 1-55. Instituto de Biología, UNAM.

Niembro R.A. 1993. Campeche en Flor. Universidad Autónoma de Campeche, Dirección General de Estudios de Posgrado e Investigación. Centro de Investigaciones en Bosques Tropicales. Campeche, Campeche, México. 225p.

Palacios-Chavez R. 1984. La morfología de los granos de polen de 
las especies mexicanas del género Bursera. Biótica 9:153-182

Palacios-Chávez R., Ludlow-Wiechers B. y Villanueva R.G. 1991. Flora Palinológica de la Reserva de la Biosfera de Sian Ka'an Quintana Roo. Centro de Investigaciones de Quintana Roo. México. 321p.

Pedraza R.A. 1983. Estudio palinológico de la familia Convolvulaceae en México: 1. Géneros Ipomea L. y Turbina Raf. Biótica 8:387-411.

Punt W., Blackmore S., Nilsson S. y Thomas L.A. 1994. Glossary of pollen and spore terminology. LPP Contributions Series No.1, International Federation of Palinological Societies, 71p.

Rico B.M. y Gómez-Pompa A. 1979. Estudio de las primeras etapassucesionales de una selva alta perennifolia en Veracruz, México. En Gómez-Pompa A., Del Amo R.S. y Vázquez-Yañez C. Eds. Investigaciones sobre la regeneración de selvas altas en Veracruz, México, pp 112-202., Consejo Nacional para la Enseñanza de la Biología, Compañía Editorial Continental. México, D.F.
Roubik D.W. y Moreno J.E. 1991. Pollen and spores of Barro Colorado Island. Monographs in Systematic Botany 36:1-270.

Rzedowski J. 1994. Vegetación de México. Editorial Limusa, S.A. de C.V. México. 432p.

Rzedowski J. y Calderón de Rzedowski G. 1996. Burseraceae. Flora de Veracruz. Fascículo 94. Instituto de Ecología, A.C.University of California. Xalapa, Veracruz. México, 37 pp.

Sánchez-Dzib Y. 2007. Morfología polínica de especies de plantas de la selva mediana subperennifolia en la Cuenca del Río Candelaria, Campeche. Tesis de Licenciatura, Universidad Autónoma de Campeche. México. 189 pp.

Wendt T. 1998. Composición, afinidades florísticas y origenes de la flora arbórea del dosel de los bosques tropicales húmedos de la vertiente mexicana del Atlántico. En: Ramamoorthy T.P., Bye R., Lot A. y Fa J. Eds. Diversidad Biológica de México. Orígenes y Distribución, pp 581-664, Instituto de Biología, UNAM, México, D.F.

Recibido: 10 de septiembre de 2008

Aceptado: 21 abril de 2009 